YAÑEZ, Rodrigo. "Una revisión crítica de los habituales conceptos sobre el íter criminis en los delitos de robo y hurto".

Polit. crim., Vol. 4, No 7 (Julio 2009), Art. 3, pp. 87-124 (1-38).

[http://www.politicacriminal.cl/Vol_04/n_07/Vol4N7A3.pdf]

\title{
Una revisión crítica de los habituales conceptos sobre el íter criminis en los delitos de robo y hurto*
}

\author{
Rodrigo Alejandro Yáñez Arriagada \\ Magíster en Derecho Penal y Ciencias Penales por la \\ Pontificia Universidad Católica de Valparaíso \\ rodrigoyanez_@hotmail.com
}

\section{Resumen}

En este artículo se analiza críticamente la visión con que se ha abordado la problemática de los delitos contra la propiedad por medios materiales. A estos efectos se analiza el alcance del verbo rector apropiar propio de la legislación chilena, y sus alcances al tiempo de encasillar a estas figuras entre los delitos de resultado o de mera actividad. Se analiza el iter criminis de estas figuras proponiendo una visión de la problemática desde la mirada del afectado y no desde el hechor como tradicionalmente se ha sostenido. Finalmente se aplica esta nueva visión a los delitos patrimoniales leves o de bagatela.

Palabras clave: apropiar, sustraer, íter criminis, delitos contra la propiedad.

\begin{abstract}
The criteria used to tackle the issue of crimes against property through material means is critically analyzed in this article. For that purpose, the reach of the rector verb appropriate, specific of Chilean legislation, is analyzed, as well as its breadth when these figures are classified between felonies of result or of mere activity. Iter criminis of these figures is analyzed, proposing a viewpoint of the issue from the victim's perspective instead of the author's, the latter being the traditional position. Finally, this new viewpoint is applied to minor or negligible patrimonial felonies.
\end{abstract}

Key words: appropriate, steal, iter criminis, crimes against property.

\footnotetext{
* Este trabajo ha sido redactado en el marco del proyecto de investigación Fondecyt $\mathrm{N}^{\mathrm{o}}$ 1070421, "Formulación de una teoría de los delitos contra el patrimonio con base en el derecho chileno: estudio dogmático y crítico", ejecutado en la Pontificia Universidad Católica de Valparaíso bajo la dirección del profesor Dr. Guillermo Oliver Calderón, en el que el autor se desempeña como ayudante de investigación.
} 
YAÑEZ, Rodrigo. "Una revisión crítica de los habituales conceptos sobre el íter criminis en los delitos de robo y hurto".

\title{
Introducción
}

\author{
"La odiosidad del hurto frente a la ley no deriva de envidia por el \\ goce que se procura el ladrón, sino de amor hacia el derecho del \\ poseedor que demanda protección." FRANCESCO CARRARA
}

Resulta fácil hoy en día observar las enormes dificultades que se están presentando diariamente en los diversos tribunales nacionales en torno a precisar exactamente cuál es el momento consumativo en algunos delitos contra la propiedad. Esta discusión se centra en la actualidad principalmente en los casos de hurto simple y de hurto falta en su forma de sustracción en tiendas de departamentos, atendida la reciente incorporación y posterior modificación del artículo 494 bis del Código Penal, como también por la existencia del inciso primero del artículo 450, que ha hecho perder relevancia a esta discusión respecto de los delitos a los que se aplica esta última norma. La generalizada diversidad de posiciones doctrinales y jurisprudenciales que han surgido llevan, hoy en día, a romper de facto el principio de igualdad ante la ley al presentarse distintas soluciones penológicas dependiendo del tribunal, y, en algunos casos, del juez concreto que resuelve la situación. Esta anomalía deviene necesariamente en inseguridad.

El gran problema se ha suscitado al recurrirse reiterada, y equivocadamente a nuestro juicio, a la búsqueda de reglas de general aplicación, con la pretensión de que la existencia de este tipo de reglas permite acercar la regulación y sanción de los delitos contra la propiedad a los fines de seguridad y de justicia. Sin embargo, esta pretensión, en este tipo de delitos, y dadas las diversas problemáticas que analizaremos a continuación, está muy lejana de la realidad. Tal vez en ningún otro grupo de ilícitos se debe aplicar con mayor severidad la máxima del limine litis.

El presente trabajo tiene por finalidad abordar los problemas que esta falta de precisión ha generado, así como proponer una alternativa de solución basada en un punto de observación objetivo externo.

No intentaremos analizar las implicancias político criminales de la delincuencia patrimonial leve, en especial la de ocurrencia en grandes establecimientos de comercio, tema que escapa por mucho a los fines de esta investigación. ${ }^{1}$ Sólo una precisión. No podemos olvidar que aunque se trate de un delito menor (desde el punto de vista de su peligrosidad y de su dañosidad individual), constituye una afectación a uno de los bienes jurídicos centrales y de mayor relevancia, cual es la propiedad. De otro lado, la tolerancia o aceptación de este tipo de acciones puede implicar una errónea lectura del nivel de protección a la propiedad, como aceptación o incluso validación de la apropiación subrepticia de bienes de escaso valor, lo que puede generar un daño intelectual grave, cual es la sensación de inseguridad colectiva frente a esta aparente insuficiente protección.

\footnotetext{
${ }^{1}$ Sobre este punto puede consultarse un extenso y completo análisis en SILVA SÁNCHEZ, Jesús - María, "Delincuencia patrimonial leve: una observación del estado de la cuestión." en: Dogmática y Criminología, dos visiones complementarias del fenómeno delictivo, Homenaje de los grandes tratadistas a Alfonso Reyes Echandía, 1ª Edición, Bogotá: Editorial Legis, 2005, pp. 567 a 588.
} 


\section{Polít. crim., Vol. 4, No 7 (Julio 2009), Art. 3, pp. 87-124 (1-38). \\ [http://www.politicacriminal.cl/Vol_04/n_07/Vol4N7A3.pdf]}

\section{Delitos de robo y hurto. Definiciones legales y origen histórico}

Tal como acertadamente detalla el profesor Rodríguez Devesa, ${ }^{2}$ ya en el Derecho Romano encontramos por primera vez las referencias al delito de hurto, como una figura básica que incluye robos con fuerza, violencia e intimidación, apropiación indebida, de cosas perdidas, de uso, y algunas figuras de estafa. Se trataba en aquella época de una agresión privada que abarcaba toda apropiación ilegítima de una cosa mueble ajena, de su uso o de su posesión. Sólo la evolución posterior permitió la diferenciación de las diversas figuras, manteniéndose eso sí hasta el día de hoy la definición básica.

En aquella época la primera distinción surgió entre hurto manifiesto (algunas incipientes figuras de robo) y no manifiesto, sosteniéndose esencialmente esta distinción en el mayor reproche al primero, fundado en la violencia que usualmente traía aparejada la acción frontal, a rostro descubierto, lo que dio lugar al surgimiento de una primera acción pública en su denuncia y persecución. El robo, en su vertiente romana, no era sino un hurto calificado por la violencia de su ejecución.

En el derecho germánico, en cambio, el hurto es la sustracción clandestina de una cosa mueble ajena. La clandestinidad es la nota de diferenciación con el robo. El valor de la cosa hurtada permite distinguir la gravedad de la acción y la pena a aplicar. El robo, por su parte, era una sustracción abierta, manifiesta, considerado un delito menor autónomo acotado a bienes específicos, no se regulaba su pena de acuerdo al valor de la cosa, sino que se le asignaba una pena única inferior a la del hurto. El factor determinante es la ocultación propia del hurto no manifiesto, lo que lo hace más deleznable al obrarse a traición, lo que traía aparejada su mayor penalidad.

La evolución posterior y el traspaso de estas figuras, primero al derecho común y luego al español, trajo como consecuencia una mezcla de fuentes, en la cual fácilmente reconocemos que la actual valoración (mayor reproche del robo) y la nomenclatura son eminentemente romanas, mientras que el asumir a ambas figuras como dos delitos absolutamente distintos, así como en el caso del hurto la regulación de la pena por el valor de la cosa sustraída es una influencia germánica.

El ánimo de lucro como elemento surgió adicionalmente en el derecho penal alemán a fines del siglo XVIII.

Con la suma de estas influencias, pasadas por el tamiz de la legislación española, se llega al concepto contenido en nuestro Código Penal, el cual es un concepto negativo del hurto, al diferenciarlo del robo (en sus diversas modalidades) por la ausencia de elementos específicos que implican el desplazamiento de la figura. Así, el artículo 432 señala que

\footnotetext{
${ }^{2}$ RODRÍGUEZ DEVESA, José María, "Concepto de Hurto" en: Nueva Enciclopedia Jurídica, Barcelona: Editorial Francisco Six S.A., 1962, pp. 174 a 224.
} 
YAÑEZ, Rodrigo. "Una revisión crítica de los habituales conceptos sobre el íter criminis en los delitos de robo y hurto".

comete hurto quien sin la voluntad de su dueño y con ánimo de lucrarse se apropia de cosa mueble ajena sin usar violencia o intimidación en las personas o fuerza en las cosas (en la forma que determina el legislador, podríamos desde ya agregar). En los demás casos, de presentarse las exigencias correspondientes se cometerá robo. Se trata de dos delitos independientes, que protegen un mismo bien jurídico.

Por último, tradicionalmente, en la distinción o clasificación que se hace de los delitos contra la propiedad, los delitos de robo y hurto son encasillados como aquellos de apropiación por medios materiales, suponiendo una actividad física del agente o sujeto activo que se ejercerá sobre la cosa sustraída, sobre sus resguardos, o sobre la persona de su titular o de quien puede evitar la acción del agente.

\section{Verbo rector en la legislación nacional: Apropiar}

Diversas son las soluciones que se han adoptado en las distintas legislaciones al momento de optar por la elección del verbo rector en los delitos contra la propiedad. Tomar, sustraer o apoderar son algunas de las opciones que han sido elegidas. En nuestro país se optó por la expresión apropiar, con una serie de consecuencias de esta elección que pasamos a exponer.

A diferencia de nuestro país, en España se ha llegado a un relativo consenso en cuanto a que el verbo rector por ellos escogido, tomar, implica separar fácticamente una cosa del patrimonio de su dueño e incorporarla al del sujeto activo. En este sentido, el profesor Rodríguez Devesa, ha sostenido luego de un largo análisis, que "el resultado de la acción es la apropiación de la cosa". ${ }^{3}$ Sin embargo, agrega el mismo que no debe entenderse este enriquecimiento como un incremento matemático del patrimonio del autor. Se trata en realidad de que, con la sustracción, ingresa en este patrimonio un derecho real ilegalmente adquirido que antes no estaba. En base a esta consideración es que el profesor Rodríguez Devesa llega a la conclusión de que estos delitos contra la propiedad, son delitos de resultado, pues precisan una modificación en el mundo exterior distinta de la acción del sujeto activo, cual sería precisamente esta apropiación, distinta del tomar.

Así, en una primera aproximación, podemos sostener que cuando prescindimos de la apropiación como verbo rector y recurrimos a conceptos diversos, como el tomar español, que implican vinculación fáctica, material, la apropiación se desplaza de su carácter de acción a una condición de resultado, lo que, como ya anticipamos, no es menor al momento de analizar qué tipo de ilícito enfrentamos.

Ahora bien, este relativo consenso no se encuentra exento de problemas, puesto que no resulta pacífica la concepción del verbo rector (tomar), como asimismo su relación con el supuesto resultado (apropiarse). Tanto es así que el mismo profesor Rodríguez Devesa,

\footnotetext{
${ }^{3}$ RODRÍGUEZ DEVESA, José María, Derecho Penal Español. Parte especial, Madrid: sin editorial, $6{ }^{\text {a }}$ Edición, 1975, pp. 367 a 378
} 


\section{Polít. crim., Vol. 4, No 7 (Julio 2009), Art. 3, pp. 87-124 (1-38). \\ [http://www.politicacriminal.cl/Vol_04/n_07/Vol4N7A3.pdf]}

antes de verter los planteamientos previamente señalados en su libro sobre "Derecho Penal Español", mantenía una opinión diversa en otra obra pretérita, ${ }^{4}$ señalando que tomar es apropiarse y que "la esencia de la acción del hurto es la apropiación". En esta concepción previa sostenía el profesor español que el legislador no ha configurado la sustracción como un desplazamiento material de la cosa, sino como un desplazamiento patrimonial, donde no importa tanto el que el sujeto activo toque o deje de tocar la cosa (que, como es sabido, puede estar previamente en su poder), como que se la apropie, despojando así antijurídicamente a su legítimo propietario. La apropiación puede realizarse, y así ocurre la mayor parte de las veces, por el camino de la aprehensión manual de la cosa, pero también por otros medios. Esto impide asignar un contenido unitario y simple a la acción, que no tiene más punto de referencia, al igual que sucede en otros delitos, que el resultado. Esta concepción implicaba asumir a la apropiación no como un resultado separado de la acción, sino como un concepto macro, complejo, que implica al mismo tiempo acción y resultado.

En este escenario, si bien podemos concluir que la apropiación implica, por un lado, la aprehensión material, por otro, el desplazamiento patrimonial de la especie del afectado al hechor y, finalmente, y al mismo tiempo, el resultado de esta misma acción, no hay acuerdo sobre las implicancias de esta aseveración. Así, en la actualidad hay autores que insisten en que pese a esta identidad entre la acción y el resultado, la necesaria existencia de un desplazamiento patrimonial torna a estos delitos en figuras de resultado. Así lo sostienen, entre otros, el profesor Muñoz Conde, para quien pese a que en los delitos de apropiación por medios materiales "La acción consiste en apropiarse, es decir, en "tomar" las cosas muebles ajenas", y que "El resultado de la acción es la apropiación de las cosas", siguen siendo delitos de resultado, ya que "hace falta un desplazamiento patrimonial y exige la separación fáctica de una cosa del patrimonio de su dueño y su incorporación al del sujeto activo". En este mismo sentido, la profesora De Vicente Martínez llega a similares conclusiones, al sostener que la acción típica en estos delitos consiste en apropiarse, definiendo a esta acción como "hacerse uno dueño de alguna cosa, ocuparla, ponerla bajo su poder". Según ella, esta acción supone "un desplazamiento físico de la cosa mueble del patrimonio del sujeto pasivo al del sujeto activo". Dos son las consecuencias de esta separación: por un lado, se requiere de un acto de desposesión de la cosa y, por el otro, se requiere al mismo tiempo de su incorporación a una esfera de disponibilidad real distinta. Luego, "el resultado de la acción es la apropiación de la cosa", lo que torna estos delitos en delitos de resultado, "ya que hace falta un desplazamiento patrimonial y exige la separación física de una cosa del patrimonio de su dueño y su incorporación al del sujeto activo". 6

Podemos atisbar, desde la óptica extranjera, que la apropiación como concepto tiende a ser considerada a la vez acción y resultado, aun cuando no hay acuerdo respecto de las

\footnotetext{
${ }^{4}$ RODRÍGUEZ DEVESA, “Concepto de Hurto”, cit. nota No 2, p. 197.

${ }^{5}$ MUÑOZ CONDE, Francisco, Derecho Penal, parte especial, 16 a Edición revisada y puesta al día, Valencia: Tirant Lo Blanch, 2007, pp. 374 y 375 (el destacado en el original).

${ }^{6}$ DE VICENTE MARTÍNEZ, Rosario, El delito de robo con fuerza en las cosas, Serie Colección Los Delitos, No 16. Valencia: Tirant Lo Blanch, 1999, pp. 33 y 34.
} 
YAÑEZ, Rodrigo. "Una revisión crítica de los habituales conceptos sobre el íter criminis en los delitos de robo y hurto".

consecuencias de esta identidad. En todo caso, indudablemente esta identidad nos dará luces sobre la clasificación de estos delitos entre aquellos que son de mera actividad o formales y los de resultado o materiales, lo que resulta de indudable importancia a los efectos del presente análisis. Ya precisaremos este punto.

En Chile, al analizar esta materia, Politoff, Matus y Ramírez sostienen que la apropiación consistiría en la "sustracción de la cosa con ánimo de señor y dueño (animus rem sibi habendi)", indicando que para los efectos de calificar el delito es indiferente el modo como se realice la sustracción, que puede ser por la simple aprehensión manual o mediante procedimientos o fuerzas extrañas a él. ${ }^{7}$ En virtud de la sustracción el sujeto activo adquiere la posesión de la cosa, en ningún caso el dominio de ella, pues el delito de hurto no es título traslaticio de dominio. En esta concepción observamos un importante problema, pues el hacer sinónimos apropiación y sustracción no nos parece adecuado ni conveniente, atendida la redacción del artículo $470 \mathrm{n}^{\circ} 1^{8}$ En efecto, esto produciría una distorsión en la inteligencia de la norma sobre la apropiación indebida. Sustracción es específico, tal vez más adecuado a los fines del 432, pero mientras mantengamos la actual redacción de la figura de apropiación indebida, parece más adecuado entender la apropiación como un simple hacer suyo, independiente de la forma en que se haga, distinguiéndolo del sustraer, que implica acción positiva de sacar lo que antes no era suyo, concepción incompatible con la figura de apropiación indebida. De aceptarse la proposición de los profesores Politoff, Matus y Ramírez, necesariamente deberíamos definir de manera diferente el concepto apropiación a los efectos del artículo 432 y a los del $470 \mathrm{n}^{\circ} 1$, lo que no resulta deseable ni recomendable.

Por su parte, el profesor Etcheberry estima por apropiación, una "impropiedad del lenguaje", jurídicamente hablando. ${ }^{9}$ Esto, por cuanto no enfrentamos un real modo de adquirir el dominio. Se trata de la adquisición de hecho, no de derecho, de las facultades que confiere el dominio, usar, gozar y disponer libremente de la cosa, tal como legítimamente puede hacerlo el dueño, sin serlo en realidad. Insiste este autor en un punto ya esbozado, en cuanto a la errada pretensión ínsita en una interpretación, haciendo sinónimos los conceptos de apropiación y sustracción. Agrega el profesor Etcheberry los grandes problemas que presenta el pretender establecer reglas generales en esta materia, por cuanto, a su juicio, el concepto apropiación supone, por un lado, un elemento material (sustraer) y, por el otro, un elemento psíquico (ánimo de señor y dueño), y dado que el objeto material debe ser ajeno, esto implica que para poder aceptar la presencia de una apropiación, parafraseando al profesor Vivanco Sepúlveda, debe haber una "sustracción de

\footnotetext{
${ }^{7}$ POLITOFF LIFSCHITZ, Sergio; MATUS ACUÑA, Jean Pierre; RAMÍREZ GUZMAN, María Cecilia, Lecciones de Derecho Penal Chileno, parte especial Tomo II, $2^{\text {a }}$ Edición actualizada, Santiago de Chile: Editorial Jurídica de Chile, 2004, p. 306.

${ }^{8}$ Código Penal Artículo 470: Las penas del artículo 467 se aplicarán también: No 1: A los que en perjuicio de otro se apropiaren o distrajeren dinero, efectos o cualquiera otra cosa mueble que hubieren recibido en depósito, comisión o administración, o por otro título que produzca obligación de entregarla o devolverla.

${ }^{9}$ ETCHEBERRY, Alfredo, Derecho Penal parte especial, Tomo III, $3^{\text {a }}$ Edición revisada y actualizada, Santiago de Chile: Editorial Jurídica de Chile, 2001, p. 297.
} 
Polít. crim., Vol. 4, No 7 (Julio 2009), Art. 3, pp. 87-124 (1-38).

[http://www.politicacriminal.cl/Vol_04/n_07/Vol4N7A3.pdf]

una cosa de la esfera de resguardo de una persona, con el ánimo de comportarse de hecho como propietario de ella", ${ }^{10}$ concepto que integra los elementos psíquico y material a lo cuales hemos hecho referencia. Como la esfera de resguardo del propietario es un concepto abstracto y su alcance, contenido y significación variará en cada situación, es necesario analizar caso a caso para determinar el límite entre los actos preparatorios y la tentativa y, evidentemente, el momento de la consumación.

Finalmente, los profesores Bullemore y Mackinnon ${ }^{11}$, al referirse a los delitos de apropiación, señalan que se trata de aquellos en que existe un "desplazamiento patrimonial de hecho, fáctico y no jurídico". Incluso llegan a sostener que se trata en el fondo de un simple desplazamiento del bien desde la esfera de resguardo del sujeto pasivo a la del sujeto activo, distinguiendo en el caso de los delitos de robo y hurto entre aquellos en que este desplazamiento se produce a consecuencia de una actividad física ejercida por el agente sobre la cosa, sobre sus medios de defensa o resguardos, o sobre el titular de ellas o sobre quien puede defenderlas.

Como primera conclusión y toma de posición, podemos sostener que apropiarse es un fenómeno complejo dirigido a hacer propio un bien mueble ajeno, lo que abarca, desde un doble punto de vista, el tomar el bien o desposesión y la expropiación del bien, que implica estar en condiciones de ejercer facultades propias del dominio sobre el objeto por parte del autor, y su correlato, la imposibilidad de que su legítimo propietario ejerza en forma libre y sin obstáculos todas o al menos alguna de las facultades propias del dominio sobre el mismo objeto material. No implica la adquisición del dominio sobre el bien, pero debe incluir la posibilidad, a lo menos potencial, de ejercer sobre la cosa alguna de las facultades del dominio en reemplazo o en lugar del legítimo propietario.

\section{Importancia de la clasificación entre delitos de mera actividad y de resultado.}

Asumiendo, como ya hemos hecho, que la sustracción supone sacar la cosa de la esfera de resguardo del titular e ingresarla a la propia por parte del hechor, y dada la relevancia que adquiere en este análisis la determinación de la forma y momento en que pretendemos exista una vulneración de esa esfera de resguardo del afectado, se hace imprescindible analizar la clasificación que distingue entre los delitos de mera actividad y de resultado y aplicarla a los delitos de apropiación por medios materiales, a fin de sostener adecuadamente una definición sobre este punto. Esta clasificación se basa en algunos aspectos que expondremos, haciendo nuestros los criterios de distinción que han señalado varios autores, nacionales y extranjeros.

\footnotetext{
${ }^{10}$ VIVANCO SEPÚLVEDA, Jaime, El delito de Robo con Homicidio, Ensayo de una interpretación a la luz de la doctrina del delito tipo, $1^{\mathrm{a}}$ Edición, Santiago de Chile: Editorial LexisNexis, Julio 2000, p. 24, citado en ETCHEBERRY, Derecho Penal, cit. nota No 9, p. 297.

${ }^{11}$ BULlEMORE, Vivian; MACKINNON, John, Curso de Derecho Penal, Tomo III, Parte Especial, $1^{\mathrm{a}}$ Edición, Santiago de Chile: Editorial Lexis Nexis, Mayo 2005, p. 72 y siguientes.
} 
YAÑEZ, Rodrigo. "Una revisión crítica de los habituales conceptos sobre el íter criminis en los delitos de robo y hurto".

El profesor Italiano Francesco Antolisei indica a este respecto, utilizando la nomenclatura italiana, que son de pura conducta (o de simple comportamiento) los delitos que "se perfeccionan con el cumplimiento de determinada acción u omisión", y se llaman de resultado, en cambio, aquellos en que, "para su consumación exigen, además, que se produzca determinado efecto, distinto de la acción u omisión". ${ }^{2}$ Agrega que en los delitos de pura conducta la hipótesis típica consiste sólo en una acción u omisión, mientras que en los delitos de resultado consiste en un comportamiento más un resultado natural del hombre. El daño o peligro previsto en los primeros surge del mero hecho de haberse observado un determinado comportamiento y en los segundos en el resultado exterior de tal comportamiento.

Sobre esta concepción, la profesora María Cecilia Ramírez ${ }^{13}$ agrega que, en el caso de los delitos de mera actividad, "éstos se perfeccionan con la sola conducta del agente sin que se requiera para ello la producción de un resultado material, no obstante lo cual, la conducta puede en determinados casos fraccionarse intelectual y físicamente". En estas figuras las formas de aparición del delito se limitan a la consumación, cuando el autor realiza todas las exigencias de la conducta ilícita, y a la tentativa, cuando el sujeto dio comienzo a la actividad pero ella no alcanza su pleno desarrollo.

Así, en el caso de los delitos de mera actividad la realización de la conducta agota la exigencia típica, lo que no implica que esta acción no pueda fraccionarse material o intelectualmente.

Cobra importancia entonces lo reseñado por el profesor español Santiago Mir Puig, en cuanto que en los delitos de mera actividad "no es necesario que la acción vaya seguida de la causación de un resultado separable espacio-temporalmente". ${ }^{14} \mathrm{Ni}$ la sola exteriorización de la conducta ni la afectación del bien jurídico son resultados, puesto que son efectos no separables espacio-temporalmente de la conducta.

Por otro lado, en los delitos de resultado el tipo exige para su consumación, además de la realización de la conducta, la realización de un resultado como efecto de tal conducta, claramente distinta de esta última, pero vinculado a aquella por una relación de causalidad ontológica. Es a lo que refiere los profesores Muñoz Conde y García Arán ${ }^{15}$ como "la realización de la acción, la producción de un resultado material de lesión o puesta en peligro de un bien jurídico". Este resultado puede ser material -como modificación del

12 ANTOLISEI, Francesco, Manual de Derecho Penal, parte general, trad. GUERRERO, Jorge; AYERRA REDIN, Marino, $8^{\text {a }}$ Edición corregida y actualizada a cargo de CONTI, Luigi, Bogotá: Editorial Temis, 1988, p. 182.

13 RAMÍREZ GUZMAN., María Cecilia, "La frustración en los delitos de mera actividad a la luz de determinadas sentencias", Revista de Derecho de la Pontificia Universidad Católica de Valparaíso, XXVI (2005 semestre I), p. 134.

${ }^{14}$ MIR PUIG, Santiago, Derecho Penal parte general, $7^{\mathrm{a}}$ Edición $2^{\mathrm{a}}$ Reimpresión, Montevideo - Buenos Aires: Editorial B de F Montevideo - Buenos Aires, Julio 2005, p. 225.

15 MUÑOZ CONDE, Francisco; GARCÍA ARÁN, Mercedes, Derecho Penal, parte general, 5ª Edición revisada y puesta al día, Valencia: Tirant Lo Blanch, 2002, p. 262. 
exterior-, o inmaterial o normativo, cuya comprobación se extrae luego de valorar situaciones jurídicas.

La acción, entonces, en los delitos de mera actividad, aun cuando sea fraccionable, divisible, intelectual o físicamente, satisface per se la descripción típica, no en el entendido de que no se precise de un resultado, sino en el entendido de que la acción típica es al mismo tiempo acción y resultado. Si la descripción típica pretende evitar la realización de una acción concreta (injuriar, asociar ilícitamente), lo hace porque precisamente la realización de tal acción, la ejecución de ésta, genera el efecto dañoso o configura la situación de peligro que se pretende evitar. Así las cosas, es erróneo sostener que en los delitos de mera actividad no existe un resultado, lo que no hay es un resultado distinto o separable de la mera actividad típica.

Compartimos por ende plenamente los términos en que esta distinción se plantea por el profesor Gustavo Labatut Glena, quien concluye que:

"Son delitos materiales aquellos cuya consumación exige la producción del evento determinado por la ley, el cual, aunque vinculado causalmente con la acción, constituye un momento distinto y posterior a ella; en otros términos, en que la acción y el resultado representan dos etapas sucesivas, perfectamente diferenciadas. En cambio se reserva la denominación de delitos formales para aquellos en que la acción coincide con el resultado, que se produce con la simple actuación del hechor, aunque no sea seguida del efecto que se pretendía obtener". ${ }^{16}$

\section{Aplicación de la clasificación a los delitos de robo y hurto.}

Tradicionalmente se ha sostenido que tanto el hurto como las diversas figuras de robo son delitos materiales o de resultado, precisamente porque hace falta un desplazamiento patrimonial. En palabras de Binding, es una expropiación y la coetánea apropiación de la $\cos a .^{17}$

Cuando se sostiene que los delitos de apropiación por medios materiales son delitos de resultado, lo que se está aseverando es que está fuera de toda duda que no es suficiente en ellos una simple manifestación de voluntad. No está prohibida por la ley la simple exteriorización del deseo de apropiarse de una cosa mueble ajena, sino que se requiere precisamente que esa apropiación genere una salida de la especie de la esfera de resguardo de un sujeto (pasivo) e ingrese a la del sujeto activo como producto de la acción por éste realizada.

\footnotetext{
${ }^{16}$ LABATUT GLENA, Gustavo, Derecho Penal Tomo I, $9^{\text {a }}$ edición actualizada por el profesor Julio Zenteno Vargas, Santiago de Chile: Editorial Jurídica de Chile, 2002, página 182.

${ }^{17}$ BINDING, Lehrbuch, I (1902) Página 169; citado por RODRÍGUEZ DEVESA en Derecho Penal Español, cit. nota $\mathrm{N}^{\circ} 3$, p. 362 y p. 378. Con mayor detalle en la nota $\mathrm{n}^{\circ} 5$ de la primera página señalada: "El autor no tiene que sustraer al propietario su propiedad, sino sólo la cosa, pero ésta con el mismo resultado de hecho que si aquel hubiera perdido el derecho. El derecho debe hacerse ilusorio".
} 
YAÑEZ, Rodrigo. "Una revisión crítica de los habituales conceptos sobre el íter criminis en los delitos de robo y hurto".

Según esta postura, si bien en algunos casos este efecto de apropiación-expropiación no es perceptible, e incluso no es separable fácticamente de la acción desplegada, es fácilmente comprobable su ocurrencia a través de la observación que se realiza sobre las facultades que el sujeto pasivo tiene sobre la cosa. Acaecido el hecho prohibido, este último pierde las facultades de usar, gozar o disponer o a lo menos alguna de éstas, lo que implica la vulneración de su esfera de resguardo.

Luego, según esta visión, se ha venido sosteniendo tradicionalmente que el resultado ha de considerarse producido cuando el sujeto activo haya adquirido sobre la cosa aquella disponibilidad inherente a la incorporación a su patrimonio. No se precisa un real y efectivo aprovechamiento de la cosa (delito agotado).

"Basta la mera posibilidad de disponer para poder hablar de disponibilidad; es suficiente con que el agente pueda destruir la cosa, consumirla o menoscabarla, aunque no llegue a hacerlo, para que haya la disponibilidad que caracteriza a la incorporación de la cosa al patrimonio del sujeto activo. Son posibles, por ende, la frustración y la tentativa". ${ }^{18}$

Estos criterios no aparecen del todo errados en una descripción normativa sustentada en el verbo rector tomar y asumiendo que el resultado de éste es apropiar, tal y como señalamos previamente. Sin embargo, al cambiar la hipótesis normativa a apropiar (Primera toma de posición: fenómeno complejo dirigido a hacer propio un bien mueble ajeno), el panorama varía, puesto que lo que el profesor Rodríguez Devesa describía como un resultado distinto de la acción, se transforma en parte de la acción misma. Es decir, que el sujeto activo haya adquirido sobre la cosa aquella disponibilidad inherente a la incorporación a su patrimonio es, a la vez, la acción reprochada y el resultado de la misma. El profesor Rodríguez Devesa reseña un punto sobre el cual más tarde la profesora García Arán pondrá el acento, que se torna de vital importancia y sobre el cual volveremos más adelante, cual es que "una clara medida de la afectación es la imposibilidad del propietario de ejercer las prerrogativas del dominio sobre el objeto de su propiedad". ${ }^{19}$

En Chile, los detractores de esta postura tradicional han desarrollado una línea argumentativa a propósito del delito de hurto, indicando que éste es un delito de mera actividad, puesto que no requiere para su consumación de la producción de un resultado que escape al control del autor. Al decir de la profesora María Cecilia Ramírez ${ }^{20}$, la consumación en el hurto requiere que la cosa objeto material del delito salga de la esfera de custodia del legítimo tenedor, pero, a su vez, esto precisa que sea el propio autor el que traslade el objeto fuera de dicha esfera hasta situarla en un lugar en el que pueda disponer de ella, cuestión que no queda entregada a un suceder causal sino a su control. Así, cada vez que el autor haya puesto todo de sí para realizar la acción típica, el delito se consuma,

\footnotetext{
${ }^{18}$ RODRÍGUEZ DEVESA, “Concepto de Hurto”, cit. nota No 2, p. 199.

${ }^{19}$ GARCÍA ARÁN, Mercedes, Delito de hurto. Serie Colección Los Delitos, No 14, Valencia: Tirant Lo Blanch. 1998, pp. 93 y ss.

${ }^{20}$ RAMÍREZ GUZMAN, “La frustración en los delitos”, cit. nota No 13.
} 
no teniendo cabida un resultado que queda a merced del acaso, por lo que el delito se puede presentar o consumado o tentado, mas no frustrado.

Agrega el profesor Héctor Hernández Basualto ${ }^{21}$ que el hurto es manifiestamente un delito de lesión, pues la apropiación de la cosa ajena lesiona efectivamente el vínculo entre ésta y su titular, pero una cosa muy distinta es que sea un delito de resultado, para lo cual lo único decisivo es si, además de la conducta de apropiación, el tipo requiere que esa conducta produzca algo distinto de ella misma, cual no es el caso. La conducta de apropiación tiene efectos que podrían sugerir la presencia de un resultado, como por ejemplo, la pérdida de la cosa por el titular o la lesión del bien jurídico. Pero para que estos efectos técnicamente constituyan un resultado se requiere que además de ser exigidos por la ley, sean distinguibles y separables de la conducta misma. Si no se logra el desposeimiento no implica que no se consuma, sino que no se ha desarrollado íntegramente la conducta típica, lo que desplaza de la frustración a la tentativa.

Todo este escenario invita a asumir una segunda conclusión y toma de posición, cual es que en general aquellas figuras de apropiación en que la propiedad es el bien jurídico casi exclusivamente protegido, son delitos de mera actividad, por cuanto al describirlos utilizando el verbo rector apropiarse (que como ya vimos no podemos asimilar a sustracción) se describe una conducta por la cual se saca una cosa de la esfera de resguardo de su legítimo tenedor, y se incorpora a la del hechor, de inmediato, sin solución de continuidad. No hay espacios en blanco ni actos consecutivos, sino que al momento que el bien mueble sale de una esfera de resguardo necesariamente ingresa a la otra. Esto hace que no se observe en ellos un resultado distinguible o separable espacio-temporalmente de la conducta misma. En lo concreto, la especie o se apropia al ejecutarse íntegramente la idealización de la conducta diseñada por el autor, o no se apropia por no ejecutarse íntegramente tal conducta, sea debido a su inidoneidad, desistimiento o intervención de terceros, que impidieron que la conducta se acabara. El lucro, luego, puede no observarse, en términos económicos, pero la figura como tal se consumó (pensemos en la rápida acción y reacción de la víctima que recupera sus atributos del dominio sobre la cosa).

Hay autores, como los profesores Politoff, Matus y Ramírez, que en base a estas argumentaciones concluyen que los delitos de apropiación son todos ellos de esta clase ${ }^{22}$, es decir, de mera actividad. Creo que, a la luz de la casuística contenida en el Título IX del Libro II del Código Penal, una generalización como ésta no es adecuada.

En efecto, hay algunas figuras en las cuales, por existir una afectación o puesta en peligro de carácter exclusivamente patrimonial, y tomando en consideración al alcance del vocablo apropiar que ya hemos definido a estos efectos, no cabe sino concluir que se trata de delitos de mera actividad. Tal es el caso del hurto simple, del hurto agravado y del hurto falta (Artículos 446, 447 y 494 bis).

\footnotetext{
${ }^{21}$ HERNÁNDEZ BASUALTO, Héctor, "La nueva regulación del hurto falta no consumado", La Semana Jurídica, semana del 11 al 17 de Junio de 2007, pp. 6 - 7.

${ }^{22}$ POLITOFF/MATUS/RAMÍREZ, Lecciones de Derecho Penal Chileno, cit. nota No 7. p. 309.
} 
YAÑEZ, Rodrigo. "Una revisión crítica de los habituales conceptos sobre el íter criminis en los delitos de robo y hurto".

Existe un segundo grupo de figuras que también es posible subsumir en esta clasificación, pese a tratarse de figuras que se encuentran denominadas en el código como robos, lo que supone la idea a priori de que existe un reproche mayor al del hurto y que se pretende evitar la afectación o amenaza a otros bienes jurídicos además de la propiedad. Por lo menos así parece. Es el caso del robo por sorpresa y de las figuras básicas del artículo 443 inciso $1^{\circ}$.

En el caso específico del robo por sorpresa, desde la incorporación de esta figura con la Ley $\mathrm{N}^{\mathrm{o}} 11.625^{23}$ se discutió sobre su ubicación asistémica, puesto que, en primer término, fue agregada al artículo 436 junto al robo con violencia; en segundo término, se le considera como robo -lo que tácitamente indica que no lo es- y, por último, se le castiga con una pena indudablemente inferior a la de las demás figuras de robo, lo que ha llevada a la conclusión casi unánime en la doctrina de que enfrentamos una figura de hurto agravado, agravado en razón de la puesta en peligro a la integridad corporal de la víctima, atendida la especial entidad de la esfera de resguardo en que se llevan, portan o ubican las cosas sustraídas, esto es, el cuerpo del afectado, puesta en peligro que por lo demás jamás se transformará en atentado de consideración a la integridad de éste, puesto que este cambio en el ánimo del hechor, y por consiguiente en el desarrollo de los acontecimientos, mutaría la figura a robo con violencia, en los amplios términos del artículo 439. Tratándose por ende de una figura que protege casi exclusivamente el patrimonio, y en mérito de las consideraciones expresadas a propósito de la elección del verbo rector apropiar (fenómeno complejo dirigido a hacer propio un bien mueble ajeno), no cabe sino concluir que se trata de una figura de mera actividad.

En el caso del robo de especies que se encuentran en bienes nacionales de uso público, del artículo 443 inciso $1^{\circ}$, figura introducida por la misma Ley $\mathrm{N}^{\circ} 11.625$, se trata de una figura creada para sancionar especialmente la apropiación de automóviles y otros vehículos motorizados estacionados en la vía pública, sus partes y piezas, así como los objetos en ellos dejados, y que, de no existir esta figura, se castigaría como hurto, tal y como se hacía antes de su incorporación ${ }^{24}$. En esta descripción típica se contiene la apropiación de especies cuya relevancia, y justificación para mantenerla entre los robos, estriba en su ubicación espacial al momento de la comisión del ilícito, unida a la especial forma de fuerza física sobre la misma cosa o sobre sus protecciones, por lo que indudablemente se trata de proteger únicamente la propiedad ${ }^{25}$. En este caso el mayor reproche de la figura

\footnotetext{
${ }^{23}$ Ley N 11.625 de Estados Antisociales, de 4 de octubre de 1954.

24 Así sostienen BULLEMORE/MACKINNON, Curso de Derecho Penal, cit. nota No.11, p. 95, y LABATUT GLENA, Derecho Penal Tomo I, cit. nota No 16, p. 209, entre otros.

${ }^{25}$ Discrepamos en este punto con los profesores BULLEMORE y MACKINNON, quienes estiman que debe exigirse asimismo, como condición adicional en esta figura, que la especie sustraída se encuentre unida permanentemente al terreno, que "formen parte del bien nacional". Esta exigencia fundada en evitar una excesiva amplitud de la figura aleja absolutamente esta norma de los precisos fines para los cuales fue creada, y determina que la apropiación de especies no unidas permanentemente sea siempre hurto, aun cuando exista una evidente fuerza dirigida ex profeso a vencer resguardos o protecciones incluso eminentemente temporales, como candados de teléfonos públicos desmontables o cadenas y candados de bicicletas; y por otro lado, supone la ampliación del alcance de la figura típica al aplicarla a casos evidentes de hurto, como el
} 


\section{Polít. crim., Vol. 4, No 7 (Julio 2009), Art. 3, pp. 87-124 (1-38). \\ [http://www.politicacriminal.cl/Vol_04/n_07/Vol4N7A3.pdf]}

surge del esfuerzo superior del hechor al sobrepasar los límites del hurto (descuido de la víctima) y actuar ex profeso rompiendo o vulnerando los especiales cuidados que el afectado pone en el resguardo de sus propiedades, reproche que trae aparejada una mayor penalidad respecto del hurto simple. En todo caso, se trata evidentemente de un delito de mera actividad, puesto que no hay un resultado observable y separable espaciotemporalmente de la propia acción. El eventual daño a la propiedad que se cause para lograr la apropiación es absorbido por la figura de robo, atendida su mayor penalidad, por regla general. Se trata de un concurso aparente de tipos penales, que debe resolverse en este caso concreto por aplicación del principio de consunción. ${ }^{26}$

La publicación, en junio de 2008, de la Ley $\mathrm{N}^{\mathrm{o}} 20.273^{27}$ generó una anomalía en esta figura al reemplazar su inciso segundo, estableciendo una figura calificada de robo en bienes nacionales de uso público (o en sitios no destinados a la habitación) ${ }^{28}$, calificación que se relaciona única y exclusivamente con un resultado distinto y adicional a la apropiación cual es "que se produzca la interrupción o interferencia del suministro de un servicio público o domiciliario". La existencia de un resultado adicional, distinto de la apropiación, una modificación en el mundo exterior adicional a ésta nos lleva a pensar que en el caso de la figura agravada podríamos enfrentar una hipótesis de figura de resultado. Sin embargo, aún no hemos recibido jurisprudencialmente el alcance de esta nueva figura agravada, y sin ser nuestro ánimo el profundizar en el análisis de la misma por ahora, caben una serie de interrogantes que aún no avizoran respuesta. A la sazón, ¿Enfrentamos una figura calificada por el resultado o el dolo del agente debe abarcar la intención copulativa de apropiarse e interrumpir o interferir el servicio?, ¿Se trata de una figura preterintencional que requería de una especial regulación atendido que se rompe la regla de que el resultado no querido es el mas gravoso?, ¿Quién es el afectado por esta figura, la empresa que no podrá cobrar por el servicio o el particular que no recibe la prestación del servicio, o ambos?, ¿Se trata de una figura dolosa o asistimos a la creación de una nueva figura cuasidelictual? Por ahora estas grandes nuevas interrogantes y otras aún no atisban una respuesta.

Para el caso del robo en sitios no destinados a la habitación vale todo lo previamente señalado, con la sola diferencia de la naturaleza privada del espacio en que se encuentra la especie sustraída, espacio eso sí abierto o con mínimas medidas de resguardo para evitar el acceso a él.

\footnotetext{
ejemplo que dan estos autores de la sustracción de una ampolleta de un alumbrado público, o incluso del foco completo, el cual si no está resguardado y se vulnera dicho resguardo en la especial forma establecida en el artículo 443 (uso de llaves falsas o verdaderas que se hubiere substraído, de ganzúas u otros instrumentos semejantes o si se procede, mediante fractura de puertas, vidrios, cierros, candados u otros dispositivos de protección o si se utiliza medios de tracción), supone únicamente la perpetración de un delito de hurto.

${ }^{26}$ Opina en este sentido, entre otros ZAFFARONI, Eugenio Raúl, Manual de Derecho Penal, parte general,

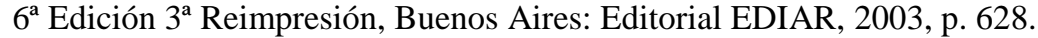

${ }^{27}$ Ley $\mathrm{N}^{\circ} 20.273$ de 28 de junio de 2008.

${ }^{28}$ Artículo 443 inciso $2^{\circ}$ del Código Penal, modificado por la Ley № 20.273: "Si con ocasión de alguna de las conductas señaladas en el inciso anterior, se produce la interrupción o interferencia del suministro de un servicio público o domiciliario, tales como electricidad, gas, agua, alcantarillado, colectores de aguas lluvia o telefonía, la pena se aplicará en su grado máximo."
} 
YAÑEZ, Rodrigo. "Una revisión crítica de los habituales conceptos sobre el íter criminis en los delitos de robo y hurto".

Finalmente en el caso de los hurtos de cosas que forman parte de redes de suministro de servicios públicos o domiciliarios, figura introducida mediante la incorporación del artículo 447 bis por la ya referida Ley $\mathrm{N}^{\mathrm{o}} 20.273^{29}$, nuevamente enfrentamos, en su inciso $1^{\circ}$, una situación de afectación exclusiva de la propiedad, y por ende una clara figura de mera actividad. Al optarse por usar como verbo rector el concepto hurtar, extiende a esta figura todas las consideraciones ya hechas respecto del verbo rector apropiar propio del hurto. Sin embargo, esta nueva descripción implica un cambio frente a la tradicional redacción de las figuras de hurto contenidas en el Código Penal, al prescindir del valor de la cosa sustraída como baremo de reproche, estableciendo una pena única independiente del valor de la especie sustraída. Además, adolece en su inciso $2^{\circ}$ de las mismas implicancias, aún no resueltas, reseñadas a propósito de la nueva figura de robo en bien nacional calificado, pues establece una figura de hurto agravado también de discutible técnica legislativa. No es esta la ocasión de profundizar sobre esta nueva figura, baste con señalar por ahora que nuevamente la existencia de un resultado adicional, distinto de la apropiación, una modificación en el mundo exterior adicional a ésta, nos lleva a pensar que en el caso de la figura agravada podríamos enfrentar una hipótesis de figura de resultado.

Distinta es la situación cuando enfrentamos figuras esencialmente pluriofensivas y complejas. Cuando la descripción típica pretende proteger otros bienes jurídicos además de la propiedad, el atentado o puesta en peligro de ese otro bien jurídico debe ser considerado como una nueva arista del análisis, lo que lleva a conclusiones diversas que impiden generalizar.

En el caso de la figura de robo con violencia o intimidación del artículo 436 inciso $1^{\circ}$, enfrentamos una figura compleja, un tipo conformado por una pluralidad de actos, cada uno constitutivo de un delito autónomo, debiéndose, para la consumación de la figura compuesta, realizar las dos o más acciones típicas. Se trata, la nueva figura, en palabras de los profesores Muñoz Conde y García Arán, de un "complejo delictivo autónomo distinto". ${ }^{30}$ En este caso concreto, los actos unidos bajo esta figura serían maltrato de obra con resultado lesivo (en los casos en que se presenta este resultado lesivo) y apropiación de especies, y en el caso del robo con intimidación se trata de una amenaza acompañada de la apropiación.

En el caso del robo con violencia, ésta se ejerce sobre la víctima y se utiliza como el medio apto para garantizar la apropiación, sea antes del robo para facilitar su ejecución, en el acto de cometerlo o después de cometido para favorecer su impunidad. ${ }^{31}{ }^{32}$ En este caso la

\footnotetext{
${ }^{29}$ Artículo 447 bis introducido al Código Penal por ley 20.273: "El hurto de cosas que forman parte de redes de suministro de servicios públicos o domiciliarios, tales como electricidad, gas, agua, alcantarillado, colectores de aguas lluvia o telefonía, será castigado con presidio menor en sus grados medio a máximo. Si con ocasión de alguna de las conductas señaladas en este artículo se produce la interrupción o interferencia del servicio, la pena se aplicará en su grado máximo."

${ }^{30}$ MUÑOZ CONDE/GARCÍA ARÁN, Derecho Penal, parte general, cit. nota Nº 15, p. 263.

${ }^{31}$ Artículo 433 Código Penal.
} 


\section{Polít. crim., Vol. 4, No 7 (Julio 2009), Art. 3, pp. 87-124 (1-38). \\ [http://www.politicacriminal.cl/Vol_04/n_07/Vol4N7A3.pdf]}

apropiación se rige por las reglas previamente desarrolladas, entendiendo que se trata de una acción única que no admite frustración. Pero la violencia, en cualquiera de las formas que se presente -con exclusión de las especialmente consideradas en los numerales del artículo 433, que desplazan la acción a robo calificado-, se rige por reglas diversas. En general, las acciones lesivas requieren de un resultado lesivo, por lo menos así es en la regulación nacional del delito de lesiones, que incluso supedita a este resultado la calificación jurídica de la figura y su penalidad. Cabría preguntarse si esta regulación es aplicable a este caso. Estimamos que no, y esto surge del artículo 439 del Código Penal, el cual sólo exige, para entender la presencia de la violencia, la existencia de malos tratamientos de obra, que implican acción lesiva sin referirse a un resultado lesivo, siendo este último un resultado distinto de la acción propiamente tal. Luego, la forma menos gravosa para el afectado que podemos claramente observar como constitutiva de violencia a estos efectos-, sería aquella en que el sujeto pasivo es empujado, sujetado, detenido, registrado, sin ser golpeado, y sin que se le cause lesión alguna con estas acciones descritas, y de este modo se le priva de los objetos de su propiedad. La apropiación propia del robo se encuentra agotada y perfecta sin requerir un resultado lesivo. Esto implica que en aquellos casos en que dicho resultado lesivo sí se presenta, sólo podría ser considerado a los efectos del artículo 69 del Código Penal como una mayor extensión del daño causado, pero no como un resultado diverso de la apropiación, puesto que su ausencia no impide la consumación de la figura. Por el contrario, si la violencia desplegada sobre la persona de la víctima no fue suficiente para permitir el éxito de la apropiación, la figura se encuentra tentada, puesto que no hubo tal apropiación, la cosa no fue sacada de la esfera de resguardo del propietario e ingresada a la del hechor, lo que puede no acaecer a pesar de que el resultado lesivo sí se presente. Luego, en el caso de esta figura lo determinante sigue siendo, sin lugar a dudas, la apropiación, y por ende, valga lo ya referido, nos enfrentamos a una figura de mera actividad.

En el caso de la figura de robo con intimidación del mismo artículo 436 inciso $1^{\circ}$, tratándose de una figura pluriofensiva y compleja similar a la anterior, reiteramos lo ya referido en términos generales, con la salvedad que desarrollaremos a continuación. En este caso la acción intimidante debe, de acuerdo a lo que señala el artículo 439 del Código Penal, estar dirigida a "hacer que las especies se entreguen o manifiesten o para impedir la resistencia u oposición a que se quiten”. En el primer caso -entrega o manifestación-, esta acción se relaciona con la oportunidad que determina el artículo 433 del mismo cuerpo legal, el que indica que la intimidación puede en primer término ejercerse "antes del robo para facilitar su ejecución o en el acto de cometerlo". Mediante la acción intimidatoria, entonces, se tiene acceso a la cosa mueble, y se llega a la apropiación mediante la disminución o desaparición de la posible defensa del afectado, o bien, en el caso de la manifestación o entrega, mediante la aparición en el afectado de una supuesta voluntad de poner término al vínculo de protección de la especie a favor del hechor, decisión

\footnotetext{
${ }^{32}$ Una opinión distinta plantea el profesor Guzmán Dálbora, para quien la acción violenta o intimidatoria ejercida con posterioridad a la apropiación sólo es admitida como constitutiva de robo a efectos de la figura calificada del artículo 433, por las razones que expresa. GUZMÁN DÁLBORA, José Luis, Estudios y defensas penales, Santiago de Chile: Editorial Lexis Nexis, 2005, p. 327.
} 
YAÑEZ, Rodrigo. "Una revisión crítica de los habituales conceptos sobre el íter criminis en los delitos de robo y hurto".

determinada por la amenaza proveniente del mismo sujeto activo. Claramente la acción central en ambos casos sigue siendo la apropiación, dejando al efecto intimidatorio en un segundo plano, pues si no se logra la apropiación, aun cuando la acción intimidatoria se encuentre acabada, el delito no puede estar consumado.

Ahora bien, la acción intimidatoria genera un efecto de la misma naturaleza en la víctima, efecto inmediato e inseparable de la acción misma. Si la acción intimidatoria no genera ese efecto, no implica falta de desarrollo o desarrollo incompleto de la acción, sino falta de aptitud para alcanzar ese objetivo. El efecto intimidatorio en estos casos es parte de la acción, es un efecto de la misma no separable espacio-temporalmente, puesto que su presencia determina la idoneidad de la acción, su capacidad para alcanzar el objetivo deseado, en este caso, la apropiación. Así las cosas, el delito de robo con intimidación en estos dos primeros casos es un delito de mera actividad.

En el tercer caso, esto es, cuando la acción intimidatoria se realiza "para impedir la resistencia u oposición a que se quite", la situación cambia diametralmente. En efecto, esta forma de comisión del artículo 439 se relaciona con la oportunidad descrita en el artículo 433, en cuanto la acción intimidatoria se despliega "después de cometido para favorecer su impunidad". De acuerdo a esto, debe existir una apropiación previa, de algún modo diverso a la intimidación, y luego desarrollarse la acción intimidatoria con la finalidad de evitar la reacción del afectado.

Lo primero que cabe preguntarse es qué tipo de acción de apropiación puede ser desarrollada antes de la acción intimidatoria en los términos recién expuestos. Sobre este punto comenzamos por descartar la intimidación como forma de apropiación, pues de presentarse esta situación, la acción intimidatoria dirigida a obtener la apropiación de la cosa o su manifestación o entrega, desplaza necesariamente la figura a esa forma específica por un principio de especialidad, tratándose evidentemente de hipótesis alternativas incompatibles entre sí. ${ }^{33}$ Luego, la apropiación debe haberse producido antes, en forma perfecta, de algún modo que no sea mediante el uso de intimidación, y esta intimidación posterior muta esa figura originaria y la reconduce al robo con intimidación.

Del mismo modo hay que descartar, por su especial naturaleza y gravedad, al robo con violencia como figura originaria. Evidentemente, resulta de mucho mayor entidad la afectación real de la integridad física de la víctima o la presencia de maniobras dirigidas a ésta (aun cuando, como señalamos, no se produzca el resultado lesivo) que la simple amenaza propia de la acción intimidatoria. Objetivamente, se trataría en el fondo de una amenaza de inferir al afectado un mal, luego de haberlo agredido para lograr la apropiación, es decir, la amenaza de una nueva agresión para terminar con cualquier defensa posterior,

\footnotetext{
${ }^{33}$ Lo que Mayer denomina delitos con resultados vinculados de manera casuística o alternativa, y que importan que la misma amenaza penal rige alternativamente para diversos casos o para diversas variantes de un caso. MAYER, Max Ernst. Derecho Penal, parte general, trad. POLITOFF LIFSCHITZ, Sergio, Colección Maestros del derecho Penal No 25, Montevideo - Buenos Aires: Editorial B de F, Julio 2007, p. 157.
} 


\section{Polít. crim., Vol. 4, No 7 (Julio 2009), Art. 3, pp. 87-124 (1-38). \\ [http://www.politicacriminal.cl/Vol_04/n_07/Vol4N7A3.pdf]}

lo que a los efectos de la tipicidad de la conducta debe resultar indiferente, salvo a los efectos del artículo 69 del Código Penal.

Luego, las formas de apropiación que podemos enfrentar en esta hipótesis, hechos los descartes mencionados, son exclusivamente las figuras de robo con fuerza en las cosas, en cualquiera de sus formas, el robo por sorpresa y el hurto.

Ahora bien, en cada uno de estos casos, la apropiación, del modo que respectivamente corresponda, se ha perfeccionado, y es, como ya hemos referido, una acción-resultado en sí misma, que determina que estas figuras sean por sí solas de mera actividad. Empero, la intimidación en este caso concreto genera y requiere de un resultado distinto de la sola apropiación, cual es el nacimiento de la sensación de temor, sea en el afectado o en terceros que a su ayuda concurren, temor de ser afectados en su integridad corporal, en su libertad personal, o que sean afectados del mismo modo sus seres cercanos, o incluso el temor de ver afectada su propiedad sobre otras especies no sustraídas, lo que les determina en definitiva a cesar en su intervención.

De esta forma, para encontrarnos con la figura de robo con intimidación, en su variante de acción intimidatoria posterior a la apropiación, necesariamente requerimos de un resultado distinto de la apropiación, un cambio en el ánimo del afectado o de un tercero que pretendía socorrerlo. Se trata de un cambio en el mundo exterior diverso de la acción intimidatoria desarrollada, y por cierto de la apropiación, por lo que no podemos sino concluir que esta especial forma de comisión del robo con intimidación es un delito de resultado, que admitiría por ende frustración cuando, por ejemplo, producida la apropiación, ante la reacción del afectado, la acción intimidatoria desplegada por el hechor no es suficiente para hacerlo desistir en su acción defensiva, o no es suficiente para evitar que recupere la especie sustraída.

Los casos de robos con fuerza en lugar habitado, en lugar destinado a la habitación, en las dependencias de ambos, y en lugar no habitado, establecidos en los artículos 440 y 442, son figuras muy similares entre sí a los efectos de este análisis. Así, en ellos se protege la propiedad sobre objetos que se encuentran a cubierto, a resguardo, al interior de alguno de los espacios especialmente protegidos por estas normas. El fundamento del mayor reproche respecto del hurto se encuentra no en la lesión a bienes jurídicos accesorios de menor entidad que la propiedad a estos efectos, como la privacidad del domicilio, su inviolabilidad, o el daño que se causa a las protecciones a través de las diversas formas de fuerza que establece el código. El mayor reproche surge de la puesta en peligro potencial a la integridad corporal de eventuales ocupantes del bien raíz en el cual se encuentran las especies, y por eso varía la penalidad dependiendo de la mayor o menor posibilidad de tal presencia, desde el robo en lugar habitado al no habitado. ${ }^{34}$ En este contexto, sigue siendo

\footnotetext{
${ }^{34}$ En contra Mera Figueroa, para quien el único fundamento del mayor reproche que suponen las figuras de robo con fuerza es precisamente el hecho de afectarse otros intereses, como la privacidad del hogar o la misma propiedad a través de los daños causados para ingresar o apropiarse de las especies. Sostiene que este mayor disvalor es representable al hechor vía agravantes genéricas o vía concurso de delitos, sin requerirse
} 
YAÑEZ, Rodrigo. "Una revisión crítica de los habituales conceptos sobre el íter criminis en los delitos de robo y hurto".

la apropiación el núcleo esencial de la acción. Si habiendo personas presentes éstas ven afectada su integridad corporal por el obrar del agente, entonces la figura de robo con violencia, simple o calificado (dependiendo del resultado lesivo y modalidad de comisión) desplaza a la figura de robo con fuerza, por lo que el peligro siempre será eso, peligro, para poder mantenernos en estas figuras de los artículos 440 y 442 . Entonces, siendo la apropiación la esencia de la descripción típica, resultan del todo aplicables los planteamientos ya vertidos, tratándose por ende de delitos de mera actividad. Cosa distinta en estos casos es cuándo entenderemos que las especies son sacadas de la esfera de resguardo del propietario, y si esta sacar jurídico debe o no ser acompañado del sacar fáctico que implica extraer las especies desde el interior de la propiedad a su exterior u otro destino. Este punto lo abordaremos más adelante, por ahora baste la aplicación de la clasificación.

El grupo de figuras más difíciles de encasillar en esta clasificación está compuesto por aquellas que se encuentran en el artículo 433, ambos numerales. Se trata de las figuras de robo con violencia o intimidación cuando con motivo u ocasión de este, se cometiere, además, homicidio, violación, castración, mutilación o lesiones graves gravísimas; o bien si la víctima fuere retenida bajo rescate o por más de un día o se cometieren lesiones simplemente graves.

Como delitos complejos que son, estas figuras jurídicas constan de la unificación de dos infracciones, cuya fusión da nacimiento a una figura delictiva nueva, superior en gravedad a las que la componen, tomadas aisladamente ${ }^{35}$. Estrictamente son formas concursales. Esta situación, que ya observamos en las figuras de robo con intimidación, robo con violencia y algunas formas de robo con fuerza, en cada caso fue resuelta entendiendo que el disvalor asociado a la violencia (lesión o maltrato de obra) o a la fuerza (violación de morada o daño) era absorbido por la figura compleja de robo respectivo, que la abarca. Se trata de incorporar en la descripción típica el presunto plan del autor, incluyendo en el mismo todas las acciones desplegadas por el hechor, en su contexto natural, sin la descontextualización que supondrá el desmembramiento de éstas y su castigo a título de concurso real. ${ }^{36} \mathrm{Si}$ alguna de estas acciones, individualmente consideradas, es a su vez típica a otro título (lo que en el caso del robo calificado es efectivo en todos los supuestos), esto resulta indiferente, pues precisamente la voluntad del legislador en esta situación es la expresada. Prescindimos entonces de las formas aisladas y consideramos y castigamos las acciones en su conjunto y en su contexto íntegro.

recurrir a estas figuras. MERA FIGUEROA, Jorge, "Protección penal de la propiedad y posibilidades rectificadoras de la dogmática, El caso del Robo con violencia o intimidación", Cuadernos de Análisis Jurídico $N^{o} 21$ Universidad Diego Portales, (1992), p. 54.

${ }^{35}$ El profesor Guzmán Dálbora, citando al profesor Luis Jiménez de Azua, los conceptúa como "delitos compuestos", dado que "los elementos que le integran figuran, además, como tipos autónomos en el propio cuerpo legal o en leyes especiales, o cuando una cierta agravante se ha elevado a característica de una infracción calificada". GUZMÁN DÁLBORA, Estudios y defensas penales, cit. nota $\mathrm{N}^{\circ} 32$.

${ }^{36}$ Así claramente lo entienden MAURACH KARL, Reinhart; GÖSSEL, Heinz; ZIPF, Heinz. Derecho Penal parte general, tomo 2 Formas de aparición del delito y las consecuencias jurídicas del hecho, trad. BOFILL GENZSCH, Jorge, Buenos Aires: Editorial Astrea, 1995 p. 530. 


\section{Polít. crim., Vol. 4, No 7 (Julio 2009), Art. 3, pp. 87-124 (1-38). \\ [http://www.politicacriminal.cl/Vol_04/n_07/Vol4N7A3.pdf]}

En los casos del artículo 433 se requiere, por tanto, de un dolo en el agente que abarque la comisión de ambas figuras delictivas, la de apropiación y la especialmente descrita en cada una de las tipificaciones a que el artículo 433 hace referencia. Esto implica en el fondo un doble dolo o, más correctamente, un dolo que abarque ambas voluntades. Y exige la realización de dos acciones distintas, punibles por separado, severamente por lo demás. Ahora bien, manteniendo la postura que hemos sostenido de que las figuras de apropiación son de mera actividad, lo que resta es analizar si esta situación especial de doble dolo o voluntad compuesta que debe abarcar el agente, genera algún efecto respecto de la clasificación analizado. Creemos que esto es así.

De hecho, todas las figuras a las que se hace referencia en el artículo 433 como calificantes son consideradas por separado delitos de resultado, que exigen una modificación en el mundo externo más allá de la acción del agente y de la cual es consecuencia. Esto redunda en que perfectamente puede consumarse la apropiación y frustrase la calificación (por ejemplo, acción homicida o lesiva interrumpida por atención médica oportuna, o fuga del sujeto retenido antes de las 24 horas). En estos casos, más allá de las dificultades probatorias que normalmente redundarán en la recalificación del hecho a la figura de robo con violencia simple, no podemos sino concluir que los especiales efectos a que hace indirectamente referencia el artículo 433 tornan a estas figuras en delitos de resultado.

\section{Límite inferior. Actos preparatorios y tentativa. Problemas del artículo 444 (presunción legal) y 445 (anticipación punitiva-actos preparatorios) del Código Penal.}

Indispensable, a la vez que indiscutidamente dificultoso, resulta determinar el ámbito de punibilidad en los delitos de apropiación, es decir, cuándo aceptamos que dejamos atrás los actos preparatorios e iniciamos a lo menos actos directos o ejecutivos (tentativa), y cuándo esa tentativa llegará a buen puerto (en la visión del sujeto activo) y se consumará la acción delictiva.

Siguiendo al profesor Carnevali, quien cita al profesor Serrano-Piedecasas:

"Debe establecerse un juicio de peligrosidad de la acción ejecutada por el agente, valorada ex-ante, sobre la base de un juicio que emite un observador imparcial, con los conocimientos propios del autor. Es preciso además determinar si tal acción conlleva un grado de peligrosidad que permita afirmar ex-post el juicio de peligro, o sea, la puesta en peligro del bien jurídico." 3738

\footnotetext{
${ }^{37}$ CARNEVALI, Raúl, "Criterios para la punición de la tentativa en el delito de hurto a establecimientos de autoservicio. Consideraciones político criminales relativas a la pequeña delincuencia patrimonial”, Polít. crim. $N^{o} 1$, (2006), A2, p. 12, disponible en http://www.politicacriminal.cl/n_01/pdf_01/a_2.pdf. (Ultima visita 06 de Enero de 2009).

${ }^{38}$ La primera parte corresponde a la teoría objetiva individualizadora, en la que se considera que para saber si estamos frente a un acto preparatorio o a una tentativa debemos estar al plan o proyecto del autor, pero analizándolo desde la óptica de un espectador imparcial con conocimiento de ese plan. Explican esta teoría, entre otros, MAURACH KARL/GÖSSEL/ZIPF, Derecho Penal parte general cit. nota No 36, p. 175.
} 
YAÑEZ, Rodrigo. "Una revisión crítica de los habituales conceptos sobre el íter criminis en los delitos de robo y hurto".

Luego, lo determinante es, en primer término, establecer si la acción desplegada, a los ojos del autor, es ya un inicio de la acción de apropiación que pretende concretar, y luego hacer un segundo análisis para determinar si esa acción efectivamente implicó a lo menos una puesta en peligro del bien jurídico tutelado, es decir, analizar su aptitud real para desencadenar el curso causal que el autor pretende desarrollar en pos de la consumación del delito.

Ahora bien, ya señalamos que apropiación, a los efectos del robo y el hurto, supone tomar la cosa y sacarla de la esfera de resguardo de su propietario o legítimo tenedor. El tomar la cosa es indiciario, pero no unívoco, debe ir acompañado de una finalidad lucrosa y propietaria, lo que produce el cese de la posesión del afectado, y del dominio de facto mas no jurídico (no es forma de adquirir el dominio). Probatoriamente es un escollo insalvable, y genera un gran problema de incertidumbre en cuanto los mismos actos en determinados casos serán actos impunes, en otros actos preparatorios, y en otros tentativa sancionable, dependiendo de la intención del agente. ${ }^{39} \mathrm{Y}$ luego viene el paso procesal posterior que resulta aun más difícil de sobrepasar, cual es la posibilidad de sostener y acreditar la intención detrás del acto desarrollado. Por ejemplo, el solo hecho de entrar a un supermercado será un hecho impune si se hace para comprar, sería acto preparatorio si se hace para hurtar pero aún no se ha decidido qué especie se sustraerá, y será tentativa si el ingreso obedece a la voluntad dirigida a la apropiación de uno o varios bienes muebles concretos. Objetivamente la acción es la misma, subjetivamente muy diversa. Si cambiamos el lugar a una vivienda habitada o destinada a la habitación, el solo ingreso bajo alguna de las modalidades del artículo 440 sigue siendo equívoco: puede ser impune en la hipótesis del inciso $1^{\circ}$ del artículo 145 del Código Penal ${ }^{40}$, puede ser un delito acabado (violación de morada) o puede ser un acto ejecutivo de un delito más complejo en contra de la propiedad o en contra de la persona de los moradores.

Y esto es predicable de todos los actos que habitualmente sostenemos configuran tentativa de un delito de robo o hurto, incluso los actos especialmente penados del artículo $444^{41}$. En este último caso nuestro legislador, con un claro afán de facilitar probatoriamente el castigo de las formas imperfectas de robo, presume que se trata de una tentativa el solo ingreso en las condiciones que señala, pero admitiendo que esta presunción pueda ser desvirtuada. Se

\footnotetext{
${ }^{39}$ Es lo que el profesor Garrido Montt denomina la resolución delictiva, lo que según él es el propósito o finalidad de la actividad ilícita a desarrollar, y que en la tentativa adquiere un rol fundamental, puesto que al tratarse de una actividad inacabada en su desarrollo, rara vez podrá en sí misma indicar cuál era su dirección. "Es la subjetividad que dirige ese actuar lo que precisará el sentido direccional de éste". GARRIDO MONTT, Mario, Etapas de Ejecución del delito. Autoría y participación. $1^{\mathrm{a}}$ Edición, Santiago de Chile: Editorial Jurídica de Chile, 1984, p. 87.

${ }^{40}$ Código Penal, Artículo 145. La disposición del artículo anterior no es aplicable al que entra en la morada ajena para evitar un mal grave a sí mismo, a los moradores o a un tercero, ni al que lo hace para prestar algún auxilio a la humanidad o a la justicia.

${ }^{41}$ Código Penal, Artículo 444. Se presume autor de tentativa de robo al que se introdujere con forado, fractura, escalamiento, uso de llave falsa o de llave verdadera substraída o de ganzúa en algún aposento, casa, edificio habitado o destinado a la habitación o en sus dependencias.
} 


\section{Polít. crim., Vol. 4, No 7 (Julio 2009), Art. 3, pp. 87-124 (1-38). \\ [http://www.politicacriminal.cl/Vol_04/n_07/Vol4N7A3.pdf]}

invierte el onus probandi, discutiblemente por cierto, y se obliga a demostrar al encausado que el fin por el cual ingresó al domicilio de un tercero no era el de robar.

En este estatus de ambigüedad, el tomar la cosa, el solo contacto sería en algunos casos acto preparatorio y en otros tentativa y en la gran mayoría un hecho impune, una nada jurídicopenalmente hablando. Lo esencial es establecer criterios objetivos que nos permitan, desde la visión de un tercero externo a la acción del autor, determinar en qué momento ya enfrentamos un acto ejecutivo. Y a continuación, determinar si es posible que estos criterios sean de general aplicación o deben ser establecidos casuísticamente.

Como tercera conclusión entonces asumimos, como límite inferior en la tentativa, aquel acto directa e inequívocamente dirigido a la afectación de las facultades del propietario, sin que implique la pérdida de tales facultades (afectación de su esfera de custodia o resguardo). Ya afectada esa esfera, el delito se consuma. Luego, la desposesión que supone la afectación implica la pérdida del control físico sobre la cosa, y la expropiación, la pérdida del poder jurídico inmediato sobre ella. La sola desposesión no es unívoca pero sí indiciaria, y será considerada tentativa en algunos casos.

En este punto el profesor Carnevali pone el acento en la posibilidad de que el hechor pueda disponer de la cosa ajena, habiéndola sacado de la esfera de resguardo o custodia en que se hallaba, siguiendo la corriente jurisprudencial que fija en esta situación jurídica-fáctica el momento consumativo y, consecuente con ello, determina como comienzo de la tentativa aquel momento en que se da inicio o tiene el agente acceso inequívoco a la disponibilidad. La llama precisamente teoría de la disponibilidad ${ }^{42}$. Según esta teoría, el delito se consumaría al momento de poder disponer el agente del bien sustraído por un instante siquiera, es decir, al tiempo de poder ejercer alguna de las facultades propias del dominio. De acuerdo con esto, la tentativa debe contener acciones directamente encaminadas a esta disposición, pero sin llegar a afectar las facultades de dominio del titular, pues esto consumaría el ilícito. Difícil suponer esta situación, más difícil aún pretender su adopción como criterio general.

En efecto, si la existencia misma de las figuras de apropiación por medios materiales busca garantizar la protección de un bien jurídico, de mayor trascendencia resulta determinar cuándo el titular del bien jurídico ve afectado su ejercicio o utilización de éste, como punto de partida de la tentativa, más que desde qué momento un tercero puede violentar el mismo bien jurídico. Debe ponerse el acento no en la adquisición del bien jurídico o interés, sino en su afectación. El centro de atención debe estar en la afectación, en la pérdida del bien y no en su adquisición, puesto que en materia penal no estamos regulando o reglamentando la adquisición de bienes jurídicos, sino su protección. En este esquema, más trascendente resulta saber desde cuándo, desde qué momento exacto, se ve afectado el legítimo detentador del derecho de propiedad - o mero tenedor en su caso-. Un delito de apropiación

\footnotetext{
${ }^{42}$ Sigue el profesor Carnevali en este sentido las expresiones utilizadas en diversos fallos de la Excelentísima Corte Suprema y el sentido señalado por diversa doctrina nacional y extranjera, aun cuando no es utilizada esta denominación en otras publicaciones.
} 
YAÑEZ, Rodrigo. "Una revisión crítica de los habituales conceptos sobre el íter criminis en los delitos de robo y hurto".

no es un modo de adquirir el dominio, sino una vulneración del legítimo ejercicio de su titular.

Comparten estas críticas a la postura referida, a nivel nacional, los profesores Politoff, Matus y Ramírez, ${ }^{43}$ para quienes la teoría de la disponibilidad peca de ser extremadamente subjetivista, a lo menos la visión de ésta del profesor Mario Garrido Montt, además de criticar su errónea utilización para fundamentar algunos fallos, en que se la confunde y finalmente se le aplica erróneamente. ${ }^{44}$ En el mismo sentido Bascuñán Rodríguez, ${ }^{45}$ para quien la disponibilidad como criterio único no resulta satisfactorio e induce a errores, al plantear una visión incompleta del problema, a su juicio, casi exclusivamente aplicable a la apropiación indebida. Bastante claras resultan sobre este punto las precisiones que señala la profesora García Arán, ${ }^{46}$ quien luego de un profundo análisis de la situación española (con el verbo rector tomar como punto de referencia, como ya se señaló), concluye que el comportamiento objetivo del delito de apropiación consiste en el apoderamiento físico de la cosa acompañado de la disponibilidad sobre la misma, y que dicho apoderamiento priva de la posibilidad de disponer al legítimo titular e implica negar la propiedad del otro, que no necesariamente debe ser el afectado por la apropiación.

La disponibilidad, entendida como posibilidad de ejercer la facultad más básica propia del dominio, el disponer de la $\cos a,{ }^{47}$ se traduce en la práctica en la posibilidad, a lo menos potencial, de transferir, transmitir o incluso destruir la cosa material, o de servirse de ella para un uso no habitual o anormal, es decir, usar de la cosa de algún modo distinto o por oposición al uso y goce normal. Habitualmente esto se traduce en la destrucción de ella.

\footnotetext{
${ }^{43}$ POLITOFF/MATUS/RAMÍREZ, Lecciones de Derecho Penal Chileno, cit. nota No 7, p. 310 y nota al pie $\mathrm{N}^{\mathrm{o}} 23^{\mathrm{a}}$.

${ }^{44}$ Concretamente, el profesor Mario Garrido Montt entiende que estos delitos sólo pueden estimarse consumados cuando el delincuente se encuentra en posibilidad de ejercer la facultad de disposición sobre la cosa ajena, no siendo suficiente sacar la especie de la esfera de protección o vigilancia del dueño, sino que además debe estar en condiciones de disponer de la cosa por un instante siquiera. Sin embargo, la fundamentación esbozada en su publicación, repetida hasta la saciedad por innumerables fallos en forma casi literal, incurre en un error esencial, cual es entender el concepto de esfera de protección únicamente desde un punto de vista físico, geográfico por decirlo de algún modo, con prescindencia de categorizaciones jurídicas, como la existencia de esferas de resguardo concéntricas, o esferas de resguardo jurídicas y no materiales. En efecto, si analizamos el ejemplo que señala el mismo autor, la huida del delincuente sorprendido, quien es perseguido por el propietario, en realidad el delito puede en el caso concreto perfectamente estar consumado, si el hechor está en condiciones de destruir la cosa, usarla, consumirla, etc. Luego no es posible asumir como regla general la frustración (tentativa, más correctamente), sino que las circunstancias de cada caso determinarán el grado de desarrollo, careciendo la formulación del profesor Garrido Montt de la universalidad que quiere pretender, lo que ha llevado a su incorrecta aplicación en innumerables fallos. GARRIDO MONTT, Mario, Derecho Penal parte general, Tomo IV, $2^{\text {a }}$ Edición, Santiago de Chile: Editorial Jurídica de Chile, 2002, p. 166.

${ }^{45}$ BASCUÑ̂́N RODRÍGUEZ, Antonio, "Delitos contra intereses instrumentales", Revista de Derecho de la Universidad Adolfo Ibáñez, $N^{o} 1$ (2004), p. 300.

${ }^{46}$ GARCíA ARÁN, Delito de hurto, cit. nota No 19 , pp. 89 y ss.

${ }^{47}$ Diccionario de la Real Academia Española de la Lengua, acepción 4a "Ejercitar en algo facultades de dominio, enajenarlo o gravarlo, en vez de atenerse a la posesión y disfrute. Testar acerca de ello." Acceso en línea, http://buscon.rae.es/draeI/
} 


\section{Polít. crim., Vol. 4, No 7 (Julio 2009), Art. 3, pp. 87-124 (1-38). \\ [http://www.politicacriminal.cl/Vol_04/n_07/Vol4N7A3.pdf]}

En definitiva, como una cuarta conclusión y toma de posición, podemos asumir que lo determinante no es ya la adquisición de la disponibilidad de la cosa por parte del agente, sino la pérdida de la disponibilidad por el afectado, el que no puede recuperarla sin un mínimo esfuerzo. Lo determinante debe ser la pérdida de la posibilidad de disponer y no la adquisición del poder de hacerlo.

Esto último puede ser el factor a considerar que nos permita desentrañar este complejo escenario. Si el acento para determinar la consumación se pone no ya en la adquisición de poder sobre la cosa por parte del hechor, sino en la pérdida del mismo por el afectado, entonces tal vez con esta misma óptica podremos determinar cuándo se acaba el acto preparatorio y comienza la tentativa.

Cobra, por ende, vital importancia la voluntad del afectado, a fin de determinar el ámbito, dentro de su propia esfera de resguardo, en que está dispuesto a tolerar el acceso y circulación de terceros, y aquella porción o ámbito en que no aceptará intromisiones. Y en cada caso, el grado de afectación de su derecho de propiedad que está dispuesto a tolerar o aceptar. Evidentemente, esta manifestación de voluntad del titular debe ser exteriorizada a fin de, precisamente, cumplir con las exigencias antes criticadas de seguridad y conocimiento. Adquiere relevancia la utilización de hitos posesorios o resguardos.

El límite entre acto preparatorio y tentativa lo encontraremos, en los delitos de apropiación por medios materiales, en la vulneración de aquel espacio de especial protección que el afectado ha delimitado, vulneración realizada con la intención de apropiarse, sin que se requiera aprehensión material de la cosa ni sea esta última requisito sine qua non para plantear la existencia de la tentativa. La aprehensión material de la cosa pasa a segundo plano en este escenario, al igual que el traslado de la misma, al ser sólo considerada y considerable en determinadas circunstancias en que la víctima no haya entregado la tenencia a quien quiera ejercerla. La objetivización de estos criterios es una labor titánica si consideramos las inagotables formas de protección y vulneración que se pueden presentar. A título de ejemplo, podemos señalar algunos lugares o espacios de especial protección, en los cuales expresamente el propietario ha limitado el acceso o circulación de terceras personas, o condicionado dicho acceso al cumplimiento de ciertas formas, y cuya vulneración claramente puede sostenerse constituye un acto directo o ejecutivo, sin llegar a afectar las facultades del dominio sobre los objetos protegidos. En cada caso concreto podemos señalar que enfrentamos una tentativa de robo o hurto, si estamos en condiciones de sostener racionalmente que la acción desplegada implica un claro e inequívoco ingreso a la esfera de resguardo del afectado, sin que implique ruptura de la misma (relación entre el objeto protegido, la esfera de protección y las facultades de dominio del titular). 
YAÑEZ, Rodrigo. "Una revisión crítica de los habituales conceptos sobre el íter criminis en los delitos de robo y hurto".

\begin{tabular}{|c|c|}
\hline Hitos posesorios o resguardos ${ }^{48}$ & Actos directos a lo menos indiciarios \\
\hline $\begin{array}{l}\text { Cuerpo del afectado, bolsillos, carteras, bolsos } \\
\text { o elementos de transporte de especies. }\end{array}$ & Apertura, registro o vulneración en éstos. \\
\hline $\begin{array}{l}\text { Lugares especialmente protegidos (bóveda, } \\
\text { bodega, mostrador cerrado, domicilio } \\
\text { particular, vehículo, etc.) }\end{array}$ & Ingreso a lugares prohibidos (Artículo 444). \\
\hline Medios de protección especiales (alarmas) & Vulneración de estos medios, desconexión. \\
\hline Accesos prohibidos o limitados & Ingreso a lugares prohibidos o limitados. \\
\hline $\begin{array}{l}\text { Condiciones especiales de acceso (solicite un } \\
\text { vendedor) o de venta (envoltorios } \\
\text { predispuestos) }\end{array}$ & $\begin{array}{l}\text { Irrespeto de condiciones especiales puestas por } \\
\text { el propietario. }\end{array}$ \\
\hline
\end{tabular}

La ruptura, quiebre o vulneración de un hito posesorio o resguardo, observada desde la posición de un tercero ajeno al conflicto, clara y lógicamente puede entenderse como el principio de ejecución por actos directos a que hace referencia el artículo $7^{\circ}$ del Código Penal, siendo uno de los factores determinantes para llegar a esta conclusión la cercanía existente al verbo rector o acción central de las figuras de apropiación, como también, la habitual inexistencia de otras conductas intermedias -en los términos que plantea el profesor Sergio Politoff Lifschitz- ${ }^{49}$ entre la ruptura, quiebre o vulneración y la apropiación que le es seguida.

Al enfrentar la realización de alguno de estos actos podremos a lo menos sostener que hay principio de ejecución, siempre y cuando estemos en condiciones de concluir que no ha habido afectación de las facultades de dominio del propietario, por un lado, y que el acto está directamente dirigido a tal afectación, por el otro. Nada impide un arrepentimiento antes de la consumación, con lo que se abre espacio a la total aplicación de la teoría del desistimiento de la tentativa.

Directamente relacionado con esto, como ya adelantamos, se encuentra la figura del artículo 444 del Código Penal, que señala que:

"Se presume autor de tentativa de robo al que se introdujere con forado, fractura, escalamiento, uso de llave falsa o de llave verdadera substraída o de ganzúa en algún aposento, casa, edificio habitado o destinado a la habitación o en sus dependencias."

\footnotetext{
${ }^{48}$ Hito es un mojón o poste de piedra, por lo común labrada, que sirve para indicar la dirección o la distancia en los caminos o para delimitar terrenos. Más específicamente, mojón se entiende como una señal permanente que se pone para fijar los linderos de heredades, términos y fronteras. Diccionario de la Real Academia de la Lengua Española. Acceso en línea, http://buscon.rae.es/draeI/

${ }^{49}$ POLITOFF LIFSCHITZ, Sergio, Los actos preparatorios del delito. Tentativa y frustración. Estudio de dogmática penal y de derecho penal comparado, $1^{\text {a }}$ Edición, Santiago de Chile: Editorial Jurídica de Chile, 1999, pp.192 y ss: para quien "las acciones que estén demasiado alejadas, temporal y espacialmente, de la realización del tipo legal no pueden considerarse hechos directos, particularmente cuando requieren del actor "actos intermedios"”, agregando el mismo autor que en aquellos casos en que la conducta típica se compone de una única actividad, se hace más incierta la determinación de qué actos podemos considerar ya como principio de ejecución, pues debemos recurrir a una especie de pronóstico para calificar de tales, actos directos, aquellos que proseguidos con buen éxito conducirían a la consumación.
} 


\section{Polít. crim., Vol. 4, No 7 (Julio 2009), Art. 3, pp. 87-124 (1-38). \\ [http://www.politicacriminal.cl/Vol_04/n_07/Vol4N7A3.pdf]}

En este caso, acorde con lo que acabamos de señalar, un acto que no implica siquiera tomar contacto con las especies apropiadas o potencialmente objeto de apropiación se castiga expresamente como tentativa, entendiendo que precisamente las acciones descritas, que no son más que vulneraciones de resguardos o hitos posesorios, demuestran actuaciones contrarias a los designios del afectado. Forado, fractura y escalamiento indican ingresar por un lugar o de una manera no determinada por el afectado; uso de llave falsa o de llave verdadera substraída y no de llave entregada por la víctima para otros fines (a más de no ser parte de la tipificación del robo), la diferencia que se observa no es de forma, sino de un tinte claramente subjetivo, y nuevamente no del hechor sino del afectado. Si el destino de la realización de alguna de estas conductas no era apropiarse de especies del afectado, esto podrá probarse (defensa afirmativa - inversión del onus probandi). Esta norma no hace más que dar el carácter de tentativa a actos que parecen ser directos en los términos del artículo $7^{\circ}$, razonamiento al que de todos modos podemos llegar obviando esta disposición mediante las reglas generales de las presunciones judiciales.

Por último, la otra figura íntimamente relacionada es el artículo 445, el cual señala que:

"El que fabricare, expendiere o tuviere en su poder llaves falsas, ganzúas u otros instrumentos destinados conocidamente para efectuar el delito de robo y no diere descargo suficiente sobre su fabricación, expendición, adquisición o conservación, será castigado con presidio menor en su grado mínimo."

En este caso el legislador va más allá, o más atrás si se quiere, puesto que se trata de actos que no vulneran de manera especial los límites impuestos por eventuales afectados, sino que sólo los ponen en un potencial e indeterminado peligro. Se trata claramente de actos preparatorios que, de no existir esta norma, quedarían impunes. Ante esto, parte de la doctrina considera que enfrentamos, más que un delito autónomo, una infracción de sospecha o de peligro general ${ }^{50}$. Eso sí, el objeto debe ser inequívoco -conocidamente-, lo que objetiviza en algo lo extremadamente subjetiva que resulta esta descripción típica, una anticipación punitiva exacerbada. Por ejemplo ¿qué pasa con los que entran con bolsas vacías a un supermercado?, ¿se agregarán en algún momento a esta figura?.

\section{Consumación. Desposesión y expropiación. Espacios de protección concéntricos. Posición del afectado y no del hechor.}

En estricta relación con las consideraciones anteriores, para poder aceptar la consumación del comportamiento lesivo apropiación, tradicionalmente se ha sostenido que se requiere de la ubicación o colocación del objeto sustraído bajo el ámbito de la disponibilidad material del autor, sin requerirse de la incorporación permanente a su patrimonio.

\footnotetext{
${ }^{50}$ En este sentido QUINTANO RIPOLLÉS, Antonio, Compendio de Derecho Penal Volumen II Parte especial, $1^{\text {a }}$ Edición, Madrid: Editorial Revista de Derecho Privado, 1958, p. 322, y RODRÍGUEZ DEVESA, Derecho Penal Español, cit. nota No 3, pp. 412 y 413.
} 
YAÑEZ, Rodrigo. "Una revisión crítica de los habituales conceptos sobre el íter criminis en los delitos de robo y hurto".

El concepto de disponibilidad, al decir de la profesora García Arán ${ }^{51}$, genera un punto intermedio entre contrectatio e illatio. Descartando la mera toma de contacto con la cosa, por su desmesurado adelanto en la persecución penal, que anula además la posibilidad de la tentativa, situar la consumación en la efectiva incorporación al patrimonio del autor conduce al efecto contrario, esto es, ampliar en forma desmesurada la tentativa, retardando en exceso la consumación del delito.

La admisión de la teoría de la disponibilidad en materia de delitos de apropiación impide considerar consumada la figura con la sola desposesión tendiente a la apropiación. Además, la disponibilidad debe ser potencial, no necesariamente efectiva sobre la cosa. La tentativa, según jurisprudencia antigua, inicia al tomar contacto con la cosa.

En todo caso, siempre esta visión tradicional del problema ha puesto erróneamente el acento en la situación del hechor, en el sentido de determinar la consumación dependiendo única y exclusivamente del momento en que éste puede o no disponer, aun cuando sea de un modo exclusivamente potencial, de la especie que pretende sustraer. Esta visión es incompleta e inexacta.

Considerando que, como hemos sostenido previamente, un delito es esencialmente una acción antijurídica dirigida, en este caso en estudio, a la desposesión y posterior apropiación de un bien mueble, y asumiendo que las descripciones típicas jurídico-penales buscan garantizar la protección de un determinado bien jurídico, no resulta lógico analizar el problema de la consumación desde la óptica del autor material, buscando desentrañar la época exacta en que pudo a lo menos potencialmente disponer del bien de propiedad del afectado, puesto que esta visión implica dar mayor relevancia a la figura del imputado por sobre la del afectado, a la acción lesiva por sobre el fin de protección, y por lo demás esta visión o punto de vista no ha podido resolver el tema de la consumación ni tampoco ha establecido reglas de fácil y general aplicación.

Se hace necesario hacer un reestudio de la situación, ahora poniendo el acento no ya en la adquisición de la disponibilidad de la cosa por el hechor, sino en la pérdida de la disponibilidad por el afectado, el que no puede recuperarla sin un mínimo esfuerzo. Si rompemos este paradigma abrimos la puerta a soluciones objetivables, y por esta vía nos acercamos a la seguridad. ${ }^{52}$

\footnotetext{
${ }^{51}$ GARCÍA ARÁN, Delito de hurto, cit. nota no 19 , p. 143.

52 En este sentido, NÚÑ̃E, Ricardo C., Delitos contra la propiedad, Principios generales hurto, robo, extorsión, Buenos Aires: Editorial Bibliográfica Argentina, 1951, quien sostiene que "el hurto consiste materialmente en el desplazamiento de la cosa del poder de la víctima al del ladrón, y que la norma que lo castiga protege, precisamente, el mantenimiento de ese poder. Este poder se ofende ya con cualquier intromisión ilegítima en su esfera, pero la ofensa no está completa sino cuando el derecho protegido ha sido totalmente aniquilado. Antes de esto, se podrá hablar de tentativa, pero no de hurto consumado", agregando que "El desapoderamiento de la víctima se produce recién cuando ha sido despojada de la cosa que poseía. La consumación de este despojo determina el momento consumativo del hurto, y se realiza una vez que el perjudicado ha sido privado de la cosa" (p. 100). En contra GARCÍA ARÁN, cit. nota No 19, para quien la desposesión de la víctima y su imposibilidad de recuperar la cosa sin un esfuerzo siquiera debe ser un criterio
} 


\section{Polít. crim., Vol. 4, No 7 (Julio 2009), Art. 3, pp. 87-124 (1-38). \\ [http://www.politicacriminal.cl/Vol_04/n_07/Vol4N7A3.pdf]}

La acción típica requiere del desplazamiento de la cosa por parte del sujeto activo, trasladándola desde la esfera de dominio del dueño a la suya propia. El resultado del delito se produce cuando la cosa u objeto material abandona la esfera del dominio del afectado. Para determinar cuándo se produce la consumación lo determinante es establecer el momento exacto en el cual el afectado deja de estar en condiciones de ejercer las facultades del dominio, o a lo menos alguna de ellas, respecto del bien mueble sustraído, con absoluta independencia de si el bien ha sido tocado o trasladado de lugar por el hechor, con absoluta prescindencia de la ubicación espacial del hechor y de la especie ya en su poder.

Si bien el profesor Robles Planas estima que si la cosa no se desplaza fuera del ámbito de dominio del afectado, a lo sumo puede haber tentativa de hurto, y que si el objeto se ha ocultado (por ejemplo, en el bolsillo) sólo habrá consumación cuando el sujeto logre extraer la cosa del ámbito de dominio original, evitando así que el legítimo poseedor pueda ejercer su voluntad sobre la misma, ${ }^{53}$ la pregunta que cabe hacerse es si esta pretendida regla puede aplicarse a la generalidad de los casos, o bien si, en situaciones específicas, pierde aplicación o se torna inexacta. ¿Qué ocurre con la destrucción de la especie dentro del ámbito de dominio del afectado? ¿Qué ocurre con el consumo o inutilización de la especie dentro del ámbito de protección del afectado? ¿Debemos pretender que el delito se encuentra tentado porque la especie, ya inútil para el propietario, nunca salió de su esfera de protección, o bien debemos racionalmente sostener que tal inutilización o destrucción consuma el ilícito? Si lo observamos desde la óptica del afectado, evidentemente la ubicación espacial de la especie resulta del todo irrelevante a la hora de determinar el grado de afectación a su derecho sobre la misma, desde que al momento de no poder disponer de ésta da exactamente lo mismo cuál es el destino que de ella ha hecho el sujeto activo. Y salvo que podamos establecer y sostener una voluntad dañosa desde su origen y no propietaria, resulta evidente que el delito debe considerarse como consumado desde ese instante, con independencia de las acciones posteriores que puedan resarcir de algún modo la acción sufrida. ¿Tiene relevancia la ubicación del sujeto activo y de la especie apropiada si ésta es por ejemplo ingerida por aquél? Y no pensemos sólo en alimentos, sino en joyas o pequeños objetos de valor por su contenido o materia prima. El sujeto que ingresa a morada ajena en las formas previstas en el artículo 440 y aún en el interior se traga las joyas del afectado, aun cuando todavía se encuentre en los aposentos de la misma habitación, ha evidentemente consumado su acción de apropiación desde el punto de vista de la total imposibilidad del propietario de la especie para poder usar, gozar o disponer de la misma. Y esto no se ve afectado por la posible recuperación de la especie, el propietario no ha podido disponer aunque sea por un instante de sus pertenencias.

complementario de la disponibilidad potencial del autor, dado que, a su juicio, la desposesión de la víctima no siempre está seguida indefectiblemente de la apropiación del hechor. Sostiene que "la pérdida de disponibilidad parcial o relativa por parte de la víctima del delito, no debe sustentar la consumación. Sólo puede sustentarla cuando no sea parcial y se corresponda con la adquisición de la disponibilidad potencial por parte del sujeto activo" (p. 148).

${ }^{53}$ ROBLES PLANAS, Ricardo, Delitos contra el patrimonio (I), en SILVA SÁNCHEZ, Jesús - María. (Dir.) - RAGUÉS I VALLÈS, Ramon (coord.), Lecciones de Derecho Penal, parte especial. Barcelona: Atelier Libros Jurídicos, 2006, p. 184. 
YAÑEZ, Rodrigo. "Una revisión crítica de los habituales conceptos sobre el íter criminis en los delitos de robo y hurto".

Como contrapartida, si la especie ya tomada por el sujeto activo, trasladada de su original ubicación e incluso sacada del bien raíz o espacio de especial protección, es susceptible de recuperar por el sujeto activo en cualquier momento, bastando para esto su decisión de hacerlo, resulta asimismo del todo irrelevante el contacto del hechor con la cosa o el traslado de ésta físicamente fuera de los espacios de protección del afectado. El delito evidentemente estará tentado por no producirse la sustracción, al no haberse afectado las facultades de dominio del propietario, siempre y cuando esto sea así. Pensemos en el hurto clandestino del contenido de una cartera cuando la víctima se percata y recupera esta especie de inmediato desde las manos del hechor y sin que medie oposición. Pensemos en el sujeto activo que toma el abrigo de la víctima que ha sido dejado apoyado en una silla, que es observado en todo momento por el propietario de esta prenda y que al momento de intentar retirarse del lugar y ser descubierto simula una confusión y devuelve la especie. La víctima no perdió ni por un momento las facultades de dominio sobre su especie, aun cuando ésta fue tomada y transportada por el hechor.

En este punto cobra relevancia la utilización de los conceptos de desposesión y expropiación. Históricamente, son situaciones contemporáneas, pues al momento que se toma la cosa con ánimo de lucro se desposee y se expropia al mismo tiempo. Conceptualmente, la desposesión es un prius lógico respecto de la expropiación, es el medio por el que la expropiación se verifica en los delitos contra la propiedad por medios materiales. La propiedad y la posesión no se hallan en un mismo plano en estos delitos. La desposesión puede identificarse, en líneas generales, con la acción, y la expropiación con el resultado. Asumiendo, como ya he sostenido, que el verbo rector apropiar implica acción de hacer propio lo ajeno, la desposesión pierde toda relevancia como hecho determinante y pasa a ser sólo un acto preparatorio, indiciario o en ocasiones tentativa de la expropiación posterior, y la expropiación, por su parte, se produce de inmediato, en cuanto el afectado pierde la posibilidad de disponer libremente del bien amagado. La desposesión no adquiere otro significado que el de constituir el modo de ataque al derecho de propiedad.

Si esto lo aplicamos a la generalidad de los delitos de robo y hurto, la desposesión no pasa de ser un indicio, un acto preparatorio, tentativa o hecho impune, lo que redunda en la absoluta pérdida de relevancia jurídico-penal de ésta, salvo que lo veamos desde la óptica que he reseñado, esto es, desde la mirada del afectado y su disponibilidad sobre los bienes de su propiedad.

Desde esta última óptica, la desposesión o aprehensión material de la cosa va a ser, a lo menos, tentativa de un ataque a la propiedad, sólo cuando implique clara y objetivamente un vencimiento de los hitos posesorios o resguardos puestos por el afectado para proteger sus bienes. Y teniendo presente que el correlato de la vulneración de la disponibilidad del afectado es necesariamente la adquisición de la disponibilidad por el hechor, si se genera con esta desposesión una nueva esfera de resguardo del nuevo detentador, de origen ilegal, pero fácticamente existente, el delito se encuentra consumado. Dado que, como hemos señalado, la ubicación del bien mueble o su traslado por el hechor es irrelevante a los fines 
Polít. crim., Vol. 4, № 7 (Julio 2009), Art. 3, pp. 87-124 (1-38).

[http://www.politicacriminal.cl/Vol_04/n_07/Vol4N7A3.pdf]

de determinar la consumación, y dado que la desposesión y el vencimiento de hitos posesorios o resguardos puede darse al interior de los espacios de especial protección determinados por el afectado, esto nos lleva a sostener que es posible la existencia de esferas de resguardo dentro de otras esferas de resguardo. La existencia de esferas de resguardo concéntricas a estas alturas resulta innegable.

El acento debe ponerse, y observarse, siguiendo a la profesora española De Vicente Martínez, no en la salida física de las especies de un lugar determinado, sino en la pérdida de poder sobre esas especies. En efecto, sostiene esta autora que:

El desplazamiento físico de la cosa no precisa que ésta haya salido del espacio sobre el que se proyecta el poder patrimonial del ofendido; pero sí que haya quedado sustraída, en efecto, a ese poder del propietario.... La sustracción no ha de ser entendida exclusivamente como alejamiento de la cosa, sino que puede llevarse a cabo mediante la ocultación de la misma, allí donde la ocultación baste para separar la cosa de la "custodia" del titular e incorporarla a la del autor. ${ }^{54}$

En Chile, para sostener esta aseveración -existencia de esferas de resguardo concéntricascontamos con fundamentos jurídicos, como son, a modo de ejemplo, los artículos 436 inciso $2^{\text {o }}{ }^{5}$ del Código Penal, en que se da el carácter de esfera de resguardo al cuerpo del afectado, con independencia del lugar en el cual se encuentre; artículo $146{ }^{56}$ del Código Penal, que da el carácter de esfera de especial resguardo a la correspondencia de una persona, con independencia del lugar en que se encuentre; artículos $155^{57}$ y $156{ }^{58}$ del Código Penal, que protegen la correspondencia en cualquier lugar, etc. Lo relevante en todos estos casos radica en que, al momento de respetar la vida privada, estamos aceptando espacios de privacidad resguardados de toda intromisión externa, en cualquier lugar en que éstos se ubiquen.

Hay fundamentos fácticos, asimismo, para sostener que existen esferas de resguardo concéntricas, como los casos de los hoteles, en que cada habitación ocupada es un espacio de especial resguardo, una esfera de custodia transitoria pero protegida, o los trabajadores de casa particular con moradas al interior del lugar de trabajo, o los vehículos privados al interior de un estacionamiento público, o locales comerciales menores ubicados al interior

\footnotetext{
${ }^{54}$ DE VICENTE MARTÍNEZ, El delito de robo con fuerza en las cosas, cit. nota $\mathrm{N}^{\circ}$ 6, p. 33.

${ }^{55}$ Código Penal, artículo 436 inciso $2^{\circ}$ : Se considerará como robo y se castigará con la pena de presidio menor en sus grados medio a máximo, la apropiación de dinero u otras especies que los ofendidos lleven consigo, cuando se proceda por sorpresa o aparentando riñas en lugares de concurrencia o haciendo otras maniobras dirigidas a causar agolpamiento o confusión.

${ }^{56}$ Código Penal, artículo 146 inciso $1^{\circ}$ : El que abriere o registrare la correspondencia o los papeles de otro sin su voluntad, sufrirá la pena de reclusión menor en su grado medio si divulgare o se aprovechare de los secretos que ellos contienen, y en el caso contrario la de reclusión menor en su grado mínimo.

${ }^{57}$ Código Penal, artículo 155: El empleado público que abusando de su oficio, allanare un templo o la casa de cualquiera persona o hiciere registro en sus papeles.....

58 Código Penal, artículo 156: Los empleados en el Servicio de Correos y Telégrafos u otros que prevaliéndose de su autoridad interceptaren o abrieren la correspondencia o facilitaren a tercero su apertura o supresión....
} 
YAÑEZ, Rodrigo. "Una revisión crítica de los habituales conceptos sobre el íter criminis en los delitos de robo y hurto".

de otros locales mayores, etc. Como se puede observar, la realidad nos demuestra que la existencia de estos espacios es más común de lo que parece.

El profesor Etcheberry acepta la existencia de estas dobles esferas de protección, entendiendo que el concepto de esfera de resguardo es abstracto y su significación concreta variará en cada caso; de este modo, es posible que en ciertas circunstancias el poder de hecho sobre la cosa pueda adquirirse con la simple remoción (amotio) de la misma, pero ello no ocurrirá siempre y necesariamente. La mayoría de las veces será a través de la ablatio. De hecho, precisamente sostiene la existencia de esta teoría de la doble esfera de protección en base a consideraciones relativas a la posición del sirviente en la casa de su patrón, quien puede esconder especies en sus ropas, enseres personales o habitación. ${ }^{59}$

Podemos sintetizar todo lo previamente expuesto en las palabras del profesor Robles Planas, quien señala que:

“...los delitos de apoderamiento por medios materiales castigan la realización de acciones de desplazamiento posesorio sobre cosas ajenas que generan situaciones fácticas a partir de las cuales el sujeto puede ejercer un determinado dominio sobre ellas, como si fuera su propietario, de modo tal que sólo se llega a lesionar la propiedad a través de la lesión previa de la posesión en la medida en que con ésta se expresa un poder fáctico sobre la cosa tendiente a impedir la actuación de otra voluntad de dominio sobre ella (la del legítimo propietario o tenedor). Con esto, la propiedad del afectado se hace ilusoria". ${ }^{60}$

\section{Situación especial del llamado hurto hormiga.}

El hurto hormiga, denominación referida a los delitos patrimoniales no violentos sobre especies de escaso valor, acaecidos en grandes tiendas de departamentos, o en general locales comerciales, al no resultarles aplicable el artículo 450 del Código Penal, y dadas las deficiencias legislativas, evidenciadas por la doctrina y jurisprudencia, del artículo 494 bis del Código Penal, ha sido el gran caldo de cultivo para las discusiones sobre el tema que analizamos. Mas allá de la sostenible crítica que se realiza a la nueva reglamentación del hurto falta, que tiende a regularlo como delito de acumulación, ${ }^{61}$ lo concreto es que la figura fue incorporada al catastro de las faltas penales con un claro sentido de facilitar la persecución de estas contravenciones, y aumentar el castigo a los culpables, lo que por

\footnotetext{
${ }^{59}$ ETCHEBERRY, Derecho Penal parte especial, cit. nota N ${ }^{\circ}$ 9, p. 299.

${ }^{60}$ ROBLES PLANAS, Delitos contra el patrimonio (I), cit. nota $\mathrm{N}^{\circ} 53$.

${ }^{61}$ En este sentido véase OLIVER CALDERÓN, Guillermo, "Análisis crítico de las últimas modificaciones legales en materia de hurto falta", Revista de Derecho de la Pontificia Universidad Católica de Valparaíso, XXV, (2005 semestre I), p.305 y SILVA SÁNCHEZ, Jesús - María, La expansión del derecho penal, Aspectos de la política criminal de las sociedades postindustriales. Reimpresión de la $2^{\text {a }}$ edición, Montevideo - Buenos Aires: Editorial B de F Montevideo - Buenos Aires: Marzo 2006, pp. 143 y ss.
} 
Polít. crim., Vol. 4, No 7 (Julio 2009), Art. 3, pp. 87-124 (1-38).

[http://www.politicacriminal.cl/Vol_04/n_07/Vol4N7A3.pdf]

diversos motivos, principalmente relacionados con las falencias legislativas demostradas, no se ha conseguido. ${ }^{62}$

La jurisprudencia sobre este punto ha sido errática, estimando en algunos casos que enfrentamos un delito de resultado y no de mera actividad ${ }^{63}$, considerando que el delito se consuma al tiempo de poder disponer el delincuente a lo menos por un momento de la especie sustraída ${ }^{64}$, siguiendo claramente al profesor Mario Garrido Montt, como expresamente lo han señalado. En general, se llega a la conclusión de que lo decisivo es la aprehensión material de la cosa y su traslado, puesto que asumen que ésta debe ser necesariamente sacada del establecimiento de comercio para consumar la figura, impidiendo esta consumación la intervención de los guardias de seguridad y sosteniendo que si se ha traspasado la línea de cajas al tiempo de la intervención del personal de seguridad, el delito se entiende frustrado. ${ }^{65}$

No podemos sino discrepar del tratamiento jurisprudencial que se ha dado a la resolución de estos casos, puesto que se ha incurrido en una serie de desaciertos. En primer término, evidentemente, a la luz de todo lo latamente referido, no es sostenible pretender que estos delitos, los hurtos simples y hurtos faltas sean delitos de resultado, y por ende no admiten frustración. Si no aceptamos la posibilidad de que se encuentra consumado, pero existieron actos ejecutivos, necesariamente los delitos se encuentran en grado de tentativa a lo menos. En segundo término, plantear un límite espacial para la determinación de un estado de

${ }^{62}$ Sobre al análisis de las modificaciones al delito de hurto falta, véase: OLIVER CALDERÓN, "Análisis crítico de las últimas modificaciones", cit. nota No 61; FERNÁNDEZ CRUZ, José Angel, "Sentencias sobre determinación del íter críminis en la falta de hurto cometido en supermercados (Juzgado de Garantía de Valdivia - Corte de Apelaciones de Valdivia)", Revista de Derecho (Valdivia) Vol. XVI (Julio 2004), pp. 229 a 240; FERNÁNDEZ DÍAZ, Álvaro, "Hurto-falta: Una reforma mal hecha y otra pendiente". Sentencias Destacadas 2005, (2006) $1^{\text {a }}$ Edición, Santiago de Chile: Editorial Libertad y Desarrollo, pp. 89 a 104; HERNÁNDEZ BASUALTO, "La nueva regulación del hurto falta, cit. nota $\mathrm{N}^{\circ} 21$; entre otros.

${ }^{63}$ SCS rol 5990-04 de fecha 20 de Abril de 2005, que indica en su considerando CUARTO que: "Se calificó tal hecho, como constitutivo de la falta hurto que contempla el artículo 494 bis del Código Penal y la conducta de la hechora se estimó de autora, enfatizándose que el delito quedó en grado de frustrado, puesto que la requerida puso de su parte todo lo necesario para consumar la falta, no verificándose ésta por causas independientes de su voluntad. En consecuencia, resulta que es cuestión no objetada que el hecho ilícito es constitutivo de una falta, de aquellas que tipifica el artículo 494 bis aludido y, que ésta, en su desarrollo, concluyó en etapa de frustración".

${ }^{64}$ SCS rol 1611-04 de fecha 16 de Junio de 2004, y rol 889-06 de fecha 26 de Abril de 2006. En esta última se señala en el considerando TERCERO.- "Que en efecto, los actos previos que desarrolló el inculpado, aunque tenían la aptitud para que el delito de hurto falta se consumara, las etapas ocurridas con posterioridad se volvieron ineptas para el logro de tal efecto al momento en que fue interceptado luego de traspasar las cajas registradoras, por lo que las especies sustraídas se mantuvieron aún dentro de la esfera de protección del establecimiento comercial mediante su sistema de seguridad".

${ }^{65}$ SCS rol 1630 de fecha 17 de Junio de 2004, considerando DECIMO.- "Que la infracción se produce al traspasar las cajas registradoras sin cancelar el valor de la especie, en consecuencia, hasta antes de ese momento sólo había una mera tenencia de la especie y no una posesión como señor y dueño, la que en el caso sublite, fue interrumpida por el guardia de seguridad que impidió se perfeccionara el ilícito al ver que el imputado traspasaba las cajas sin cancelar su valor, es decir, con su intervención frustró el delito, no dando pábulo al delincuente para actuar como señor y dueño". Reiterado en fallo SCS rol 5125-05 de fecha 20 de Diciembre de 2005, literalmente por lo demás. 
YAÑEZ, Rodrigo. "Una revisión crítica de los habituales conceptos sobre el íter criminis en los delitos de robo y hurto".

desarrollo de un delito, en el entendido de que mientras no se traspase la línea de cajas sólo hay mera tentativa, y una vez traspasados al ser sorprendido sólo hay frustración, está incorporando una valoración basada en un elemento externo que, como ya se ha anticipado, no tiene especial relevancia a la hora de analizar el íter críminis de estas figuras.

Lo que ocurre es que el gran problema de estos criterios jurisprudenciales es su ambición de generalidad, su búsqueda inútil de una regla de general aplicación, y la omisión por esta vía y con este fin, de una serie de datos esenciales de la causa al tiempo de valorar la acción del sujeto activo.

Una de las características esenciales de los establecimientos de comercio de esta naturaleza es la disposición de amplias salas de venta de libre acceso, en que el propietario de las especies las dispone de tal modo que invita al contacto directo entre la especie y los clientes $\mathrm{y}$, entre estos clientes, potenciales autores de ilícitos. Luego, ante esta invitación, en principio no puede considerarse el solo tomar el objeto material como un acto ejecutivo del hurto. En principio.

Ocurre que dentro de un establecimiento de esta naturaleza se dan distintas situaciones que hacen variar esta situación o regla general. A la sazón:

- Dentro de los bienes de propiedad del dueño del establecimiento hay bienes dispuestos para la venta, y bienes que no lo están. Luego, la sola aprehensión material de algún objeto no destinado a la venta puede ser un acto ejecutivo si se dan las condiciones necesarias de ese caso particular, dependiendo del tipo de objeto y demás circunstancias particulares, como la forma de traslado del mismo, por ejemplo.

- Dentro de los establecimientos de comercio el propietario habitualmente dispone de condiciones especiales de venta para especies de valores elevados, como custodia en escaparates bajo llave, utilización de mecanismos de seguridad (alarmas), determinación de especiales forma de venta (sólo con vendedor o pago dentro del establecimiento en cajas especialmente establecidas), número máximo de prendas permitidas ingresar a un probador, etc. En todos estos casos la ruptura o violación de estos hitos posesorios determina a lo menos la tentativa de la apropiación, tratándose de evidentes actos ejecutivos directos dirigidos a ésta, aun cuando la especie y el sujeto no salgan todavía del establecimiento. Queda incólume la posibilidad de desistirse de esta tentativa.

- El consumo de alimentos destinados a la venta implica una clara consumación del delito de hurto, desde el momento que el propietario no ha permitido esta situación. Otra cosa es que en la práctica opere una verdadera cláusula de arrepentimiento eficaz de facto al tiempo de permitirse y no cuestionarse el pago de la especie ya consumida. Esto obedece a que el principal interés del propietario es la venta. No nos parecería sostenible que, por ejemplo, después de cometer un robo por sorpresa, el sujeto activo regresara hacia el afectado y le pagara el importe de lo sustraído, y seguramente, salvo 


\section{Polít. crim., Vol. 4, No 7 (Julio 2009), Art. 3, pp. 87-124 (1-38). \\ [http://www.politicacriminal.cl/Vol_04/n_07/Vol4N7A3.pdf]}

para los efectos del artículo $11 \mathrm{~N}^{\mathrm{o}} 7$ ó 456 del Código Penal, no tendría ninguna relevancia jurídico-penal. Sin embargo en el caso de los hurtos en grandes establecimiento de comercio opera de este modo diverso, puesto que, por un lado, al propietario del establecimiento le interesa el pago del producto y, además, normalmente no existe ánimo de lucro en el comprador, puesto que este pretende pagar lo consumido desde un principio. Y si la voluntad de pagar el producto no existía en un origen, al vendedor le basta con que en algún momento surja y determine el pago voluntario del producto, más allá de las intenciones primeras.

- Si bien el propietario ha dispuesto las especies de forma de permitir el contacto directo de sus clientes con éstas, existen ciertas formas sociales de comportamiento en estos establecimientos que indican claramente la intención de comprar, como son la utilización para el traslado de las especies de carros o canastillos dispuestos para ello, o el simple transporte de las especies a la vista en las manos. Esto no es menor, por tratarse de una demostración de un ánimo. Cuando se incumplen estas especiales formas de traslado hay un llamado de atención, que no siempre es decisivo. Así, guardar las cosas en un bolsillo puede ser un acto impune si se hace con la finalidad de facilitar su traslado al sector de cajas. Pero hay otros casos en los cuales una acción de esta naturaleza sí puede considerarse un acto ejecutivo dirigido a la apropiación, o incluso claramente constituir apropiación, al generar una nueva esfera de resguardo en torno al objeto, como los casos en que subrepticiamente las especies son introducidas en bolsos, carteras o mochilas cerradas, o guardadas en bolsillos o mangas falsas, o incluso guardados bajo la ropa interior del hechor.

La pregunta para resolver si estas y otras acciones pueden configurar tentativa o consumación debemos analizarla desde la óptica planteada, esto es, si alguna de las facultades del dominio del propietario se ve afectada por la acción del agente. Así las cosas, en el caso del consumo de los alimentos el delito se encuentra consumado, sin lugar a dudas. Lo mismo sucede cuando las especies se ocultan en sectores de especial protección del hechor que conforman una nueva esfera de resguardo, puesto que la posibilidad de que el afectado pueda disponer de esas especies es ilusoria. Frente a quienes sostienen que esta interpretación limita en exceso el campo de la tentativa en este tipo de delitos, y en especial de su desistimiento, cabe preguntarse algo. Si aceptáramos que mientras el sujeto está circulando al interior del establecimiento con las especies ocultas en las condiciones predichas el delito se encuentra sólo en grado de tentativa, si aceptamos que al momento de ser interceptado el sujeto cuando intenta salir del establecimiento el delito aún no se ha consumado, entonces debemos asumir que cobran total aplicación las reglas del artículo 10 numerales 4, 5 y 6 del Código Penal, habilitando a, entre otras circunstancias, que el hechor sea revisado en el mismo lugar por el afectado o sus representantes para recuperar la especie en legítima defensa de su derecho de propiedad. Si reiteradamente los tribunales de alzada de nuestro país han sostenido que los guardias de seguridad de un establecimiento no tienen facultades para revisar a una persona detenida por hurto, necesariamente debemos concluir que se asume que cuando las especies están ocultas en el cuerpo o bolsos del 
YAÑEZ, Rodrigo. "Una revisión crítica de los habituales conceptos sobre el íter criminis en los delitos de robo y hurto".

hechor el delito está consumado, excluyendo por este motivo la aplicación de las reglas de le legítima defensa.

Cosa muy distinta es que el afectado espere que el hechor intente salir de la tienda para tener la certeza sobre su voluntad, pero esto obedece a evitar problemas, dado que siempre existirá la posibilidad de que el sujeto se arrepienta y devuelva la especie, dejándola dentro de la tienda, lo que no hace óbice a que el delito se haya consumado. Cosa distinta es si político-criminalmente es recomendable o deseable la persecución de este delito en estas condiciones. No debe sorprendernos esta situación, por lo demás regulada a los efectos del delito de hurto simple y robo en el artículo 456 del Código Penal. ${ }^{66}$

Por último, si el sujeto es observado poniendo las especies en el carro de supermercado, trasladándose al sector de cajas, traspasando éstas pagando sólo una parte y dejando las demás en el carro, saliendo del establecimiento al tiempo de acercarse un guardia que estuvo en todo tiempo al tanto de lo que ocurría a través del sistema de cámaras de vigilancia y comunicación interna, bastándole en cualquier momento para poner término a la acción del agente el tomar la especie del carro para devolverla a su ubicación, entonces no podemos sostener que el delito esté consumado, puesto que objetivamente la disponibilidad sobre la cosa del propietario no se vio afectada, ya que éste precisamente dispuso todo para que el hechor tomara la cosa y la trasladara y pudo recuperarla en cuanto deseó hacerlo.

Lo esencial, y es el punto sobre el cual debemos poner el acento, es que para determinar el momento de consumación de un delito de este tipo y en estas especiales circunstancias, es necesario analizar caso a caso, prescindiendo de reglas inútiles a estos efectos, como el traspaso de las líneas de cajas o la salida del establecimiento comercial. No existen, por ende, reglas generales a aplicar.

\section{Conclusiones.}

Recapitulando entonces:

- Apropiarse debemos entenderlo como un fenómeno complejo dirigido a hacer propio un bien mueble ajeno, lo que implica, desde un doble punto de vista, el tomar el bien o desposesión y la expropiación del bien. Esto supone el estar en condiciones de ejercer facultades propias del dominio sobre el objeto por parte del autor, y su correlato, la imposibilidad de que su legítimo propietario ejerza en forma libre y sin obstáculos todas o al menos alguna de las facultades propias del dominio sobre el mismo objeto material. No implica la adquisición del dominio sobre el bien, pero debe incluir la posibilidad, a lo menos potencial, de ejercer sobre la cosa alguna de las facultades del dominio en reemplazo o en lugar del legítimo propietario.

\footnotetext{
${ }^{66}$ Código Penal, artículo 456. Si antes de perseguir al responsable o antes de decretar su prisión devolviere voluntariamente la cosa robada o hurtada, no hallándose comprendido en los casos de los artículos 433 y 434 , se le aplicará la pena inmediatamente inferior en grado a la señalada para el delito.
} 


\section{Polít. crim., Vol. 4, No 7 (Julio 2009), Art. 3, pp. 87-124 (1-38). \\ [http://www.politicacriminal.cl/Vol_04/n_07/Vol4N7A3.pdf]}

- En general, aquellas figuras de apropiación en que la propiedad es el bien jurídico casi exclusivamente protegido, son delitos de mera actividad, por cuanto al describirlos utilizando el verbo rector apropiarse (que, como ya vimos, no podemos asimilar a sustracción), se describe una conducta por la cual se saca una cosa de la esfera de resguardo de su legítimo tenedor, y se incorpora a la del hechor, de inmediato, sin solución de continuidad. No hay espacios en blanco ni actos consecutivos, sino que al momento en que el bien mueble sale de una esfera de resguardo necesariamente ingresa a la otra. Esto hace que no se observe en ellos un resultado distinguible o separable espacio-temporalmente de la conducta misma. En lo concreto, la especie o se apropia al ejecutarse íntegramente la idealización de la conducta diseñada por el autor, o no se apropia por no ejecutarse íntegramente tal conducta, sea debido a su inidoneidad, desistimiento o intervención de terceros, que impidieron que la conducta se acabara. El lucro, luego, puede no observarse, en términos económicos, pero la figura como tal se consumó (pensemos en la rápida acción y reacción de la víctima que recupera sus atributos del dominio sobre la cosa).

- Configura a lo menos tentativa, y por ende, constituye el límite inferior punible, aquel acto directa e inequívocamente dirigido a la afectación de las facultades del propietario, sin que implique la pérdida de tales facultades (afectación de su esfera de custodia o resguardo). Ya afectada esa esfera, el delito se consuma. Luego, la desposesión que supone afectación implica la pérdida del control físico sobre la cosa, y la expropiación, la pérdida del poder jurídico inmediato sobre ella. La sola desposesión no es unívoca pero sí indiciaria, y será considerada tentativa en algunos casos. Lo determinante para establecer el momento de la consumación no es ya la adquisición de la disponibilidad de la cosa por parte del agente, sino la pérdida de la disponibilidad por el afectado, el que no puede recuperarla sin un mínimo esfuerzo. Lo determinante debe ser la pérdida de la posibilidad de disponer y no la adquisición del poder de hacerlo.

- La desposesión o aprehensión material de la cosa va a ser a lo menos tentativa de un ataque a la propiedad sólo cuando implique clara y objetivamente un vencimiento de los hitos posesorios o resguardos puestos por el afectado para proteger sus bienes. Y teniendo presente que el correlato de la vulneración de la disponibilidad del afectado es necesariamente la adquisición de la disponibilidad por el hechor, si se genera con esta desposesión una nueva esfera de resguardo del nuevo detentador, de origen ilegal, pero fácticamente existente, el delito se encuentra consumado.

- Lo esencial, para determinar el momento de consumación de un delito de hurto en grandes establecimientos de comercio es analizar caso a caso, prescindiendo de reglas inútiles a estos efectos, como el traspaso de las líneas de cajas o la salida del establecimiento comercial. No existen, por ende, reglas generales a aplicar. 
YAÑEZ, Rodrigo. "Una revisión crítica de los habituales conceptos sobre el íter criminis en los delitos de robo y hurto".

\section{BIBLIOGRAFÍA}

ANTOLISEI, Francesco. Manual de Derecho Penal, parte general, trad. GUERRERO, Jorge y AYERRA REDIN, Marino, $8^{\mathrm{a}}$ Edición corregida y actualizada a cargo de CONTI, Luigi, Bogota, Editorial Temis, 1988.

BASCUÑÁN RODRÍGUEZ, Antonio. "Delitos contra intereses instrumentales". Revista de Derecho de la Universidad Adolfo Ibáñez, $N^{o} 1$ (2004), pp. 291 a 345.

BULlEMORE, Vivian; MACKINNON, John. Curso de Derecho Penal, Tomo III, Parte Especial, $1^{\text {a }}$ Edición, Santiago de Chile, Editorial Lexis Nexis, Mayo 2005.

CARNEVALI, Raúl. "Criterios para la punición de la tentativa en el delito de hurto a establecimientos de autoservicio. Consideraciones político criminales relativas a la pequeña delincuencia patrimonial". Revista Política Criminal $N^{o} 1$, (2006), A2, pp. 1 a 17. disponible en http://www.politicacriminal.cl/n_01/pdf_01/a_2.pdf. (Ultima visita 06 de Enero de 2009).

DE VICENTE MARTÍNEZ, Rosario. El delito de robo con fuerza en las cosas, Serie Colección Los Delitos, N 16, Valencia, Tirant lo Blanch, 1999.

ETCHEBERRY, Alfredo. Derecho Penal parte especial, Tomo III, $3^{\text {a }}$ Edición revisada y actualizada, Santiago de Chile, Editorial Jurídica de Chile, 2001.

FERNÁNDEZ CRUZ, José Ángel. "Sentencias sobre determinación del íter críminis en la falta de hurto cometido en supermercados (Juzgado de Garantía de Valdivia - Corte de Apelaciones de Valdivia)", Revista de Derecho (Valdivia) Vol. XVI (Julio 2004), pp. 229 a 240.

FERNÁNDEZ DÍAZ, Álvaro. "Hurto-falta: Una reforma mal hecha y otra pendiente". Sentencias Destacadas 2005, (2006) $1^{\text {a }}$ Edición, Santiago de Chile, Editorial Libertad y Desarrollo, pp. 89 a 104.

GARCÍA ARÁN, Mercedes. Delito de hurto. Serie Colección Los Delitos, No 14, Valencia, Tirant lo Blanch, 1998.

GARRIDO MONTT, Mario. Derecho Penal parte especial, Tomo IV, $2^{\text {a }}$ Edición, Santiago de Chile, Editorial Jurídica de Chile, 2002.

. Etapas de Ejecución del delito. Autoría y participación. $1^{\mathrm{a}}$ Edición Santiago de Chile, Editorial Jurídica de Chile, 1984.

GUZMÁN DÁLBORA, José Luis, Estudios y defensas penales, Santiago de Chile, Editorial Lexis Nexis, 2005

HERNÁNDEZ BASUALTO, Héctor. "La nueva regulación del hurto falta no consumado". La Semana Jurídica, semana del 11 al 17 de Junio de 2007, pp. 6 y 7.

LABATUT GLENA, Gustavo. Derecho Penal Tomo I, $9^{\mathrm{a}}$ edición actualizada por el profesor Julio Zenteno Vargas, Santiago de Chile, Editorial Jurídica de Chile, 2002.

MAURACH KARL, Reinhart; GÖSSEL, Heinz; ZIPF, Heinz. Derecho Penal parte general, tomo 2, Formas de aparición del delito y las consecuencias jurídicas del hecho, Trad. BOFILL GENZSCH, Jorge, Buenos Aires, Editorial Astrea, 1995.

MAYER, Max Ernst. Derecho Penal, parte general, trad. POLITOFF LIFSCHITZ, Sergio, Colección Maestros del derecho Penal No 25, Montevideo - Buenos Aires, Editorial B de F, julio 2007. 
Polít. crim., Vol. 4, No 7 (Julio 2009), Art. 3, pp. 87-124 (1-38).

[http://www.politicacriminal.cl/Vol_04/n_07/Vol4N7A3.pdf]

MERA FIGUEROA, Jorge. "Protección penal de la propiedad y posibilidades rectificadoras de la dogmática, El caso del Robo con violencia o intimidación". Cuadernos de Análisis Jurídico $N^{o} 21$ Universidad Diego Portales, (1992), pp. 51 a 64.

MIR PUIG, Santiago. Derecho Penal parte general, $7^{\text {a }}$ Edición $2^{\text {a }}$ Reimpresión, Montevideo - Buenos Aires, Editorial B de F, Montevideo - Buenos Aires, julio 2005.

MUÑOZ CONDE, Francisco; GARCÍA ARÁN, Mercedes, Derecho Penal, parte general, $5^{\text {a }}$ Edición revisada y puesta al día, Valencia, Tirant Lo Blanch, 2002.

MUÑOZ CONDE, Francisco; Derecho Penal, parte especial, $16^{\mathrm{a}}$ Edición revisada y puesta al día, Valencia, Tirant Lo Blanch, 2007.

NÚÑEZ, Ricardo C. Delitos contra la propiedad, Principios generales hurto, robo, extorsión, Buenos Aires, Editorial Bibliográfica Argentina, 1951.

OLIVER CALDERÓN, Guillermo. "Análisis crítico de las últimas modificaciones legales en materia de hurto falta". Revista de Derecho de la Pontificia Universidad Católica de Valparaíso, XXVI, (2005 semestre I), pp. 295 a 307.

POLITOFF LIFSCHITZ, Sergio; MATUS ACUÑA, Jean Pierre; RAMÍREZ GUZMÁN, María Cecilia, Lecciones de Derecho Penal Chileno, parte especial Tomo II, $2^{\text {a }}$ Edición actualizada, Santiago de Chile, Editorial Jurídica de Chile, 2004.

POLITOFF LIFSCHITZ, Sergio, Los actos preparatorios del delito. Tentativa y frustración. Estudio de dogmática penal y de derecho penal comparado, $1^{\text {a }}$ Edición, Santiago de Chile, Editorial Jurídica de Chile, 1999.

QUINTANO RIPOLLÉS, Antonio. Compendio de Derecho Penal Volumen II Parte especial, $1^{\text {a }}$ Edición, Madrid, Editorial Revista de Derecho Privado, 1958.

RAMÍREZ GUZMÁN, María Cecilia. "La frustración en los delitos de mera actividad a la luz de determinadas sentencias", Revista de Derecho de la Pontificia Universidad Católica de Valparaíso, XXVI, (2005 semestre I), pp. 133 a 141.

ROBLES PLANAS, Ricardo, Delitos contra el patrimonio (I), en SILVA SÁNCHEZ, Jesús - María. (Dir.) - RAGUÉS I VALLÈS, Ramon (coord..), Lecciones de Derecho Penal, parte especial. Barcelona, Atelier Libros Jurídicos, 2006.

RODRÍGUEZ DEVESA, José María. Derecho Penal Español. Parte especial, sin edit., $6^{\text {a }}$ Edición, Madrid, 1975.

Concepto de Hurto en Nueva Enciclopedia Jurídica, Barcelona, Editorial Francisco Six S.A., 1962, pp. 174 a 224.

SILVA SÁNCHEZ, Jesús-María. La expansión del derecho penal, Aspectos de la polícitca criminal de las sociedades postindustriales. Reimpresión de la $2^{\text {a }}$ edición, Montevideo - Buenos Aires, Editorial B de F, Montevideo - Buenos Aires, Marzo 2006.

"Delincuencia patrimonial leve: una observación del estado de la cuestión." En Dogmática y Criminología, dos visiones complementarias del fenómeno delictivo, Homenaje de los grandes tratadistas a Alfonso Reyes Echandía, $1^{\text {a }}$ Edición, Bogotá, Editorial Legis, 2005, pp. 567 a 588. 
YAÑEZ, Rodrigo. "Una revisión crítica de los habituales conceptos sobre el íter criminis en los delitos de robo y hurto".

VIVANCO SEPÚLVEDA, Jaime. El delito de Robo con Homicidio, Ensayo de una interpretación a la luz de la doctrina del delito tipo, $1^{\mathrm{a}}$ Edición, Santiago de Chile, Editorial LexisNexis, Julio 2000.

ZAFFARONI, Eugenio Raúl. Manual de Derecho Penal, parte general, $6^{\text {a }}$ Edición $3^{\text {a }}$ Reimpresión, Buenos Aires, Editorial EDIAR, 2003. 